\title{
Myosin-driven Nucleation of Actin Filaments Drives Stereocilia Development Critical for
} Hearing

Zane G. Moreland ${ }^{\# 1,2,3}$, Fangfang Jiang ${ }^{\# 1,2}$, Carlos Aguilar ${ }^{\# 4}$, Melanie Barzik ${ }^{\# 5}$, Rui Gong ${ }^{7}$, Arik M. Cole ${ }^{5}$, Andrew Parker ${ }^{4}$, Susan Morse ${ }^{4}$, Elizabeth Wilson ${ }^{5}$, Yasuharu Takagi ${ }^{6}$, James R. Sellers ${ }^{6}$, Steve D.M. Brown ${ }^{4}$, Thomas B. Friedman ${ }^{5}$, Gregory M. Alushin ${ }^{7}$, Michael R. Bow ${ }^{4,8 *}$ \& Jonathan E. 10 Bird $^{1,2 *}$

${ }^{1}$ Department of Pharmacology and Therapeutics, and ${ }^{2}$ Myology Institute, and ${ }^{3}$ Graduate Program in Biomedical Sciences, University of Florida, Gainesville, FL 32610, USA. ${ }^{4}$ Mammalian Genetics Unit, MRC Harwell Institute, Harwell Campus, OX11 ORD, UK. '5aboratory of Molecular Genetics, National Institute on Deafness and Other Communication Disorders, National Institutes of Health, Bethesda, MD 20814, USA. 'Laboratory of Molecular Physiology, National Heart, Lung and Blood Institute, National Institutes of Health, Bethesda, MD 20814, USA. ${ }^{7}$ Laboratory of Structural Biophysics and Mechanobiology, The Rockefeller University, New York, NY 10065, USA. ${ }^{8}$ UCL Ear Institute,

\#Authors contributed equally

${ }^{*}$ Co-corresponding authors

Lead contact: j.bird@ufl.edu

24

Running title: A myosin motor regulates actin polymerization 


\section{SUMMARY}

The assembly and maintenance of actin-based mechanosensitive stereocilia in the cochlea is critical for lifelong hearing. Myosin-15 (MYO15) is hypothesized to modulate stereocilia height by trafficking actin regulatory proteins to their tip compartments, where actin polymerization must be precisely controlled during development. We identified a mutation (p.D1647G) in the MYO15 motordomain that initially maintained trafficking, but caused progressive hearing loss by stunting stereocilia growth, revealing an additional function for MYO15. Consistent with its maintenance of tip trafficking in vivo, purified p.D1647G MYO15 modestly reduced actin-stimulated ATPase activity in vitro. Using ensemble and single-filament fluorescence in vitro assays, we demonstrated that wild-type MYO15 directly accelerated actin filament polymerization by driving nucleation, whilst p.D1647G MYO15 blocked this activity. Collectively, our studies suggest direct actin nucleation by MYO15 at the

41 stereocilia tip is necessary for elongation in vivo, and that this is a primary mechanism disrupted in 42 DFNB3 hereditary human hearing loss.

43 


\section{INTRODUCTION}

Cochlear hair cells are the primary transducers of sound in the mammalian inner ear and are fundamental for hearing. Each hair cell assembles approximately 100 individual stereocilia on its apical surface to form a mechano-sensitive hair bundle. Within each bundle, stereocilia are precisely graded into ranks of ascending height and this staircase architecture is critical for mechano-electric transduction (MET) (Barr-Gillespie, 2015). The regulation of stereocilia size is thus central for hearing and the disruption of hair bundle architecture is a common theme in hereditary deafness (Richardson et al., 2011). Stereocilia develop from microvilli by building a highly cross-linked para-crystalline core of actin filaments as an internal scaffold to confer shape and structural rigidity (Vélez-Ortega and Frolenkov, 2019). As stereocilia develop, the actin core thickens and elongates to reach its mature size, necessitating precise control of actin filament polymerization (Tilney et al., 1992; Kaltenbach et al., 1994; Krey et al., 2020). Actin filaments are uniformly polarized within stereocilia with rapidly growing barbed ends orientated towards the tip, the major site of actin polymerization and filament elongation, and also the site of MET (Flock and Cheung, 1977; Tilney et al., 1980; Beurg et al., 2009). Once stereocilia are fully assembled, actin polymerization continues primarily at the tip compartment, indicating an ongoing plasticity throughout adult life (Schneider et al., 2002; Zhang et al., 2012;

Drummond et al., 2015; Narayanan et al., 2015). A number of proteins have been identified within the tip compartment that are essential for stereocilia growth, yet the molecular mechanisms governing actin polymerization are unknown. Identification of this mechanism is central to the acquisition and maintenance of hair cell mechano-sensitivity, and also for understanding hearing loss as the clinical manifestation of a cytoskeletal disease.

A key molecule in establishing stereocilia architecture is unconventional myosin 15 (MYO15), encoded by the gene Myo15 in mice and MYO15A in humans. Mutations in MYO15A (MIM \#602666) cause DFNB3 recessive hereditary hearing loss in humans (Friedman et al., 1995; Wang et al., 1998; Rehman et al., 2016). MYO15 is a member of the myosin superfamily of P-loop ATPases that generate contractile force on actin filaments to power cellular processes such as cytokinesis, endocytosis and vesicular trafficking (Hartman and Spudich, 2012; Houdusse and Sweeney, 2016). Two MYO15 isoforms are produced in auditory hair cells through alternative mRNA splicing (Liang et al., 1999; Anderson et al., 2000; Fang et al., 2015). A shorter isoform (MYO15-2, also known as MYO15-S) consists of the ATPase 'motor domain' and three light chain binding sites that associate with calmodulin-like proteins, in addition to myosin tail homology 4 (MyTH4), Src homology 3 (SH3), and protein 4.1, ezrin, radixin, moesin (FERM) domains (Fig. 1A). A larger isoform (MYO15-1, also known as MYO15-L) is identical to MYO15-2, except for the addition of a $133 \mathrm{kDa}$ N-terminal domain 
79

80

81

82

83

84

85

86

87

88

89

90

91

92

93

94

95

96

97

98

99

100

101

102

103

104

105

106

107

108

109

110

111

112

(Fig. 1A). Both MYO15 isoforms localize to the stereocilia tip compartment where actin polymerization is concentrated (Schneider et al., 2002; Belyantseva et al., 2003; Drummond et al., 2015; Fang et al., 2015; Narayanan et al., 2015). The prototypical Myo15 mutant allele, the shaker 2 (Myo15 $\left.{ }^{\text {sh2}}\right)$, prevents both isoforms from accumulating in stereocilia, blocking developmental elongation and causing profound hearing loss from birth (Probst et al., 1998; Anderson et al., 2000; Belyantseva et al., 2003; Fang et al., 2015). The use of an isoform-specific Myo15 null allele revealed additional functions, with MYO15-2 being necessary for stereocilia developmental elongation, whilst MYO15-1 independently maintains the postnatal size of shorter stereocilia (Fang et al., 2015) that are structurally plastic in response to MET (Vélez-Ortega et al., 2017; Krey et al., 2020).

The MY015-2 isoform associates with additional proteins essential for stereocilia elongation, and by inference, actin polymerization. The 'elongation complex' consists of epidermal growth factor receptor pathway substrate 8 (EPS8), whirlin (WHRN), G-protein signalling modulator 2 (GPSM2) and G-protein subunit alpha $\mathrm{i}_{3}$ (GNAI3). Similar to MYO15-2, these proteins are concentrated at the tips of the tallest stereocilia (row 1) (Mburu et al., 2003; Belyantseva et al., 2005; Delprat et al., 2005; Manor et al., 2011; Zampini et al., 2011; Tarchini et al., 2016; Mauriac et al., 2017; Tadenev et al., 2019). Individual knock-out mouse mutants of Eps8, Whrn, Gpsm2 or Gnai3 recapitulate the shaker 2 phenotype, exhibit short stereocilia and are profoundly deaf (Mburu et al., 2003; Manor et al., 2011; Zampini et al., 2011; Tarchini et al., 2016; Mauriac et al., 2017; Tadenev et al., 2019). There is strong evidence that a key function of MYO15-2 is to traffic the elongation complex and concentrate it at the stereocilia tips. First, elongation complex proteins are absent from the stereocilia of Myo15 shaker 2 hair cells, demonstrating their functional dependence upon MYO15-2 in vivo (Belyantseva et al., 2005; Delprat et al., 2005; Manor et al., 2011; Mauriac et al., 2017; Tadenev et al., 2019). Second, EGFP. tagged MY015-2 actively traffics elongation complex proteins along filopodia in cell lines (Belyantseva et al., 2005; Manor et al., 2011; Mauriac et al., 2017). Finally, enzymatic studies of the purified MYO15 ATPase domain reveal kinetic adaptations that enable long-range processive molecular trafficking (Bird et al., 2014; Jiang et al., 2021). Together, these data support MY015-2 delivering the elongation complex to the stereocilia tips, where the elongation complex is hypothesized to regulate actin polymerization. Despite its central role in promoting stereocilia growth, the specific molecular activity of the elongation complex remains unknown.

Here, we describe a novel Myo15 mutant mouse ('jordan') that exhibits progressive hearing loss resulting from a missense substitution in the MYO15 motor domain. In striking contrast with shaker 2 hair cells, MYO15 and the elongation complex proteins are still delivered to the stereocilia tip 
compartment in jordan mutant hair cells, but stereocilia fail to elongate properly. These results questioned the sufficiency of the elongation complex to drive stereocilia growth, and prompted us to search for another role of MYO15 independent of delivering the elongation complex. We found that purified MYO15 motor domain protein directly stimulated actin polymerization in vitro, and that the jordan mutation blocked this activity, whilst only moderately affecting its ability to bind and move along actin filaments. A companion structural study shows that the jordan mutation targets the actomyosin binding interface and interferes with the ability of wild-type MYO15 to regulate structural plasticity within the actin molecule itself (Gong et al., 2021). Combined, our results argue that MYO15 controls stereocilia elongation by directly regulating F-actin conformation in stereocilia, and that this critical activity is independent of the elongation complex. More broadly, our work suggests that in addition to their classical roles generating force and motility, myosin motors have a physiological role regulating actin polymerization in vivo.

\section{RESULTS}

\section{A forward genetic screen identifies jordan, a Myo15 allele causing progressive hearing loss} cohort (comprising 83 mice) was identified with 10 mice exhibiting severe hearing loss at 3-months of age (Fig. 1B). A genome scan and single nucleotide polymorphism (SNP) mapping of third generation (G3) deaf mice found linkage to a $16.7 \mathrm{Mb}$ region on Chromosome 11 (Fig. S1A). Whole-genome sequencing of a single deaf mouse identified a high confidence homozygous mutation within the critical interval, consisting of an A-to-G transition at coding nucleotide 4940 of the Myo15 gene (ENSMUST00000071880). This variant was confirmed by Sanger sequencing (Fig. S1B) and leads to the substitution of an evolutionarily conserved aspartate residue with a glycine (p.D1647G) in the encoded MYO15 protein (Fig. 1C). We named this mutant allele jordan (Myo15 ${ }^{j d}$ ).

To confirm that the Myo1 ${ }^{j d}$ substitution causes hearing loss, we performed a genetic complementation test utilizing the shaker-2 $\left(M y 015^{\text {sh2 }}\right)$ deafness allele in trans (Probst et al., 1998; Stepanyan et al., 2006). We recorded ABRs from postnatal day 28 (P28) mice and found that compound heterozygous Myo15 $1 / \mathrm{d}^{\mathrm{sh} 2}$ mice had elevated thresholds of $>90$ decibel sound pressure level

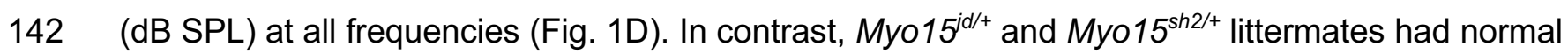
143 thresholds (<40 dB SPL) (Fig. 1D). Failure of complementation in Myo15 $5^{j / s h 2}$ mice confirms that the 144 p.D1647G mutation in Myo15 is the cause of recessive deafness in the jordan pedigree. 
All reported mutant Myo15 mouse alleles cause profound deafness (MGI:1261811), measured from P14 onwards (Probst et al., 1998; Anderson et al., 2000; Stepanyan et al., 2006; Fang et al., 2015). ABR showed that several Myo15 ${ }^{j d / j d}$ mice had residual hearing at 3 months (Fig. 1B, red circles), suggesting a distinct mechanism of hearing loss. We investigated this using longitudinal $A B R$ measurements. At 4 weeks of age, Myo15 jd/jd mice had moderate hearing loss with broadband click

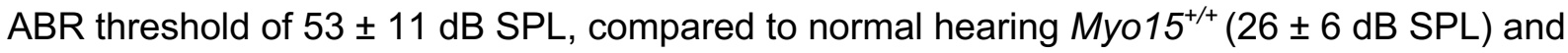
Myo15 ${ }^{+/ j d}(24 \pm 6 \mathrm{~dB}$ SPL) littermates (Fig. 1E). The hearing of Myo15 jdjjd mice progressively worsened, with click ABR thresholds of $53 \pm 11,69 \pm 9,80 \pm 9$ and $81 \pm 8 \mathrm{~dB}$ SPL at 4, 6, 9 and 12 weeks,

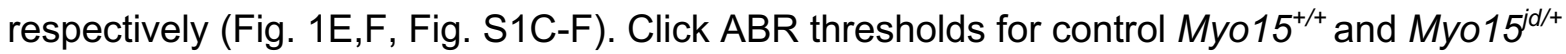
littermates ranged between $22 \pm 4$ and $26 \pm 6 \mathrm{~dB}$ SPL; showing they did not develop hearing loss with age (Fig. 1E,F, Fig. S1C-F). To investigate outer hair cell (OHC) function we measured distortionproduct otoacoustic emissions (DPOAEs), and found they were absent in Myo15jd/jd mice at 12 weeks, except for frequencies $<10 \mathrm{kHz}$, where they were significantly reduced compared to $M y 015^{+/+}$and Myo15 ${ }^{+/ j d}$ littermates (Fig. S1G). The absence of DPOAEs shows that OHC function is impaired in Myo15 jd/jd mice. As the only known mouse Myo15 variant to cause progressive hearing loss, the jordan allele is an important new model to explore the full spectrum of DFNB3 deafness, which presents heterogeneously as either profound congenital, or progressive hearing loss in humans (Rehman et al., 2016).

\section{Stereocilia do not properly elongate in jordan mutant hair cells}

To investigate the cellular pathology underlying hearing loss in Myo15 j/j/j mice, we used scanning electron microscopy (SEM) to assess the structure of cochlear hair bundles. In wild-type

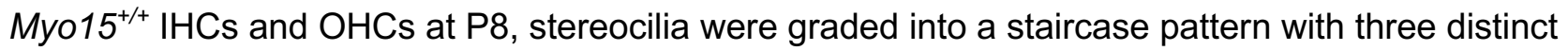
rows (Fig. 2A,B). By comparison, bundle heights were reduced in Myo15 jd/jd littermates, whilst still retaining the staircase architecture (Fig. 2C,D). Quantification of row 1 stereocilia heights showed that

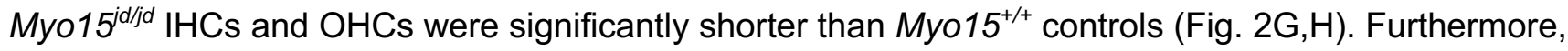
stereocilia at the lateral edge of Myo15 $5^{j / j d} \mathrm{OHCs}$, and to lesser extent IHCs, were shorter in height such that the central stereocilia were tallest (Fig. 2C,D). Myo15 jd/jd hair cells consistently had 1 or 2 additional rows of stereocilia (Fig. 2C,D) when compared to the three well-defined rows in Myo15

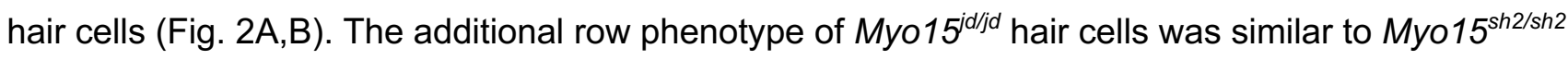
hair cells at P8 (Fig. 2E,F), however Myo15 jd/jd stereocilia lengths were significantly longer when compared to Myo15 $5^{\text {sh2/sh2 }}$ hair cells (Fig. 2G,H). We conclude that stereocilia in Myo1 $5^{\text {jd/jd }}$ hair cells elongate more than Myo15 ${ }^{\text {sh2/sh2 }}$ hair cells, but fail to reach normal wild-type heights. The Myo15 
179

180

181

182

183

184

185

186

187

188

189

190

191

192

193

194

195

196

197

198

199

200

201

202

203

204

205

206

207

208

209

210

211

212

shaker 2 and jordan allelic series shows that mutations in the motor domain led to altered stereocilia heights and explain why jordan mice initially have less severe hearing loss than shaker-2 mice.

To further investigate the progressive component of hearing loss, we next examined hair bundle morphology at 12 weeks, when jordan mice were profoundly deaf (Fig. 1F). Compared with

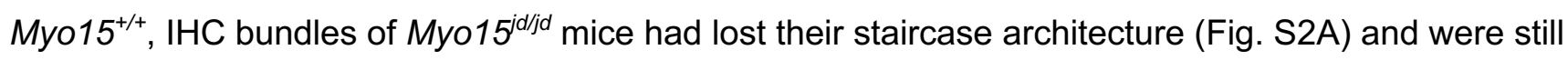
significantly shorter (Fig. S2B). Since the staircase was initially present at P8 in Myo15 ${ }^{\text {jdjd }}$ IHCs (Fig. 2D), these data suggested a postnatal resorption of stereocilia. Consistent with this hypothesis, extremely short stereocilia at the hair bundle periphery were observed at 12 weeks in Myo15 j/jd $\mathrm{OHCs}$ (Fig. S2C,D). These data argue that the progressive hearing phenotype in the jordan mouse was due to postnatal stereocilia bundle degradation. Overall, we conclude that the jordan allele causes hearing loss by interfering with both initial elongation of stereocilia, and their postnatal maintenance. This was consistent with the p.D1647G mutation targeting the motor domain of both MYO15 isoforms (Fang et al., 2015).

\section{MY015 traffics the elongation complex in jordan hair cells}

Hair bundle development requires MYO15 dependent trafficking of EPS8, WHRN, GNAI3 and GPSM2 (the 'elongation complex'), and mutations that prevent MYO15 trafficking (i.e. shaker-2) cause a short hair bundle phenotype (Belyantseva et al., 2005; Manor et al., 2011; Mauriac et al., 2017; Tadenev et al., 2019). Our finding that stereocilia lengths in the jordan mouse were only marginally longer than the shaker-2, led us to hypothesize that MYO15 trafficking was defective in jordan hair cells. We used the previously validated pan-MYO15 antibody PB48 (Fig. 1A), that binds an epitope common to all isoforms (Liang et al., 1999; Fang et al., 2015), to detect MYO15 in fixed cochleae from

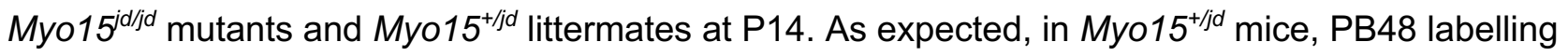
was concentrated at the tips of all stereocilia rows in IHCs (Fig. 3A) (Belyantseva et al., 2003, 2005; Rzadzinska et al., 2004). We confirmed that PB48 did not label the short stereocilia of Myo15 $5^{\text {sh2/sh2 }}$ IHCs at P14 (Fig. 3A), consistent with MYO15 being absent from the bundle (Belyantseva et al., 2003). In stark contrast with the shaker-2, we observed PB48 labelling at the tips of IHC stereocilia in Myo15 jdjj mice at both P7 and P14 (Fig. 3A,B). These data support the jordan and shaker-2 mutations affecting stereocilia growth by profoundly different mechanisms: the shaker-2 mutation blocks MYO15 trafficking, whilst the jordan mutation allows MYO15 to traffic but prevents stereocilia elongation.

We next investigated if the jordan mutation interfered with trafficking of the elongation complex

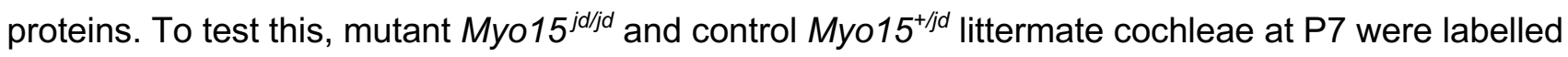


with validated antibodies to localize WHRN, EPS8, GPSM2 and GNAI3. All of the elongation complex proteins were concentrated at the tips of the tallest stereocilia (row 1) in control Myo15 $5^{+/ j d}$ hair cells (Fig. 3C), in agreement with previous work (Mburu et al., 2003; Manor et al., 2011; Zampini et al., 2011; Tarchini et al., 2016; Mauriac et al., 2017). All four proteins in the elongation complex were also targeted to the stereocilia tips in mutant $M y 015^{j d / j d}$ hair cells (Fig. 3C), although the signal-to-noise of GPSM2 and GNAI3 was lower, indicating a reduced overall accumulation (Fig. 3C). In older animals at P14, EPS8 and WHRN were still correctly targeted in Myo15 $5^{\text {jdjd }}$ hair cells, however GNAI3 and GPSM2 were no longer concentrated at stereocilia tips (Fig. S3). These data are consistent with GPSM2-GNAI3 operating as a distinct complex with MYO15-EPS8 (Tadenev et al., 2019). We conclude that the initial defective stereocilia elongation in jordan hair cells evident at P7 was not due to gross disruption of elongation complex trafficking by MYO15.

\section{Actin barbed end capping is unaffected in jordan mutant hair cells}

The presence of the elongation complex at the stereocilia tips of jordan hair cells suggested that the proteins known to stimulate growth were present, but insufficient to drive elongation. We considered whether an overall inhibition of actin polymerization was preventing stereocilia elongation in jordan hair cells. Capping proteins (CAPZ, TWF2) are present within stereocilia and regulate filament polymerization by blocking barbed end elongation (Peng et al., 2009; Avenarius et al., 2017). To detect free barbed ends, we monitored the incorporation of TMR-labelled actin monomers in permeabilized hair cells at P6. In control Myo15 $5^{+/ j d}$ hair cells, TMR-actin was concentrated at row 2 stereocilia tips revealing uncapped barbed ends (Fig. 4A). TMR-actin was not consistently detected at row 1 tips, arguing that barbed ends were inaccessible at that location (Fig. 4A). The jordan mutation did not alter this distribution of free barbed ends and we observed a similar incorporation of TMR-actin in Myo15 ${ }^{\text {ddjid }}$ hair cells compared to controls (Fig. 4A). In striking contrast, TMR-actin was incorporated at the tips of all stereocilia rows in Myo15 $5^{\text {sh2/sh2 }}$ hair cells, indicating the abnormal presence of barbed ends in row 1, and an overall loss of hair bundle row identity (Fig. 4A). In summary, jordan hair cells retain row identity at $\mathrm{P} 6$, consistent with MYO15 correctly targeting the elongation complex to the stereocilia tip compartment. These data argue that inappropriate actin filament capping is unlikely the cause of short stereocilia in jordan hair cells. Instead, we hypothesized that a stimulatory factor independent of the elongation complex was missing.

\section{The jordan mutation affects the interaction of MYO15 with actin filaments}

The jordan missense substitution is in the MYO15 motor domain helix-loop-helix (HLH) motif that forms part of the direct binding interface with the actin filament (Gong et al., 2021). We 
247 hypothesized that a defect in MYO15's interaction with actin might underlie the jordan phenotype. To 248 explore this, we examined MYO15-2 trafficking along filopodia; actin-based structures that protrude 249 from the periphery of heterologous cells (Belyantseva et al., 2003, 2005). We focused on MYO15-2 as 250 the isoform responsible for stereocilia growth (Fang et al., 2015). In transfected HeLa cells, EGFP251 tagged wild-type MYO15-2 accumulated at filopodia tips indicating robust anterograde myosin 252 movement along the filopodia shaft (Fig. 4B). Discrete puncta of MYO15-2 were observed along the 253 filopodia shaft, arising from retrograde actin filament treadmilling (Belyantseva et al., 2005; Kerber et 254 al., 2009; Bird et al., 2017). EGFP alone did not accumulate within filopodia, proving this distribution 255 required active myosin motility (Fig. 4B). In cells expressing the MYO15-2 jordan mutant, EGFP was observed diffusely along filopodia shafts and was not concentrated at filopodia tips (Fig. 4B). This was qualitatively similar to cells expressing the MYO15-2 shaker-2 mutant (Fig. 4B), which was previously shown to not traffic along filopodia (Belyantseva et al., 2005). The inability of the MYO15-2 jordan mutant to traffic within filopodia and accumulate at filopodia tips was unexpected and contrary to MYO15 protein accumulating at the stereocilia tips of Myo15 jd/jd hair cells (Fig. 3A). the appropriate repertoire of actin-binding proteins (ABPs) to support motility. To test this hypothesis, we used the porcine LLC-PK1-CL4 (CL4) epithelial cell line that generates microvilli and is a more accurate model for stereocilia (Zheng et al., 2010). In CL4 cells transfected with wild-type EGFPMYO15-2, EGFP positive puncta localized at the tips of microvilli (Fig. 4C, orthogonal projections). In striking contrast to HeLa cells, the MYO15-2 jordan mutant also concentrated into microvilli and was indistinguishable from the wild-type in CL4 cells (Fig. 4C). No microvillar accumulation of the MYO152 shaker-2 mutant was observed (Fig. 4C). We conclude that whilst jordan and shaker-2 mutants are both immobile within filopodia, the jordan mutant can still actively concentrate in microvilli. These data mimic our findings from hair cells in vivo, and support a change in actin binding as being central to the stereocilia growth defect phenotype observed in jordan hair cells.

\section{The ATPase activity of MYO15 is altered by the jordan mutation}

To study the interaction between MYO15 and actin filaments in more detail, we characterized the influence of the jordan mutation upon ATPase mechanochemistry (Bird et al., 2014; Jiang et al., 278 2021). Motor domain proteins were expressed in S. frugiperda (Sf9) insect cells and purified by chromatography (Fig. 5A,C). In contrast to the shaker-2 variant, which aggregated within Sf9 cells, both wild-type and jordan motor domains were soluble. Using size exclusion chromatography (SEC), 
we found that FLAG-purified shaker-2 motor domain eluted close to the void volume (Fig. 5B). In contrast, the jordan motor domain eluted at a similar delay volume to the wild-type (Fig. 5B), which is monomeric (Bird et al., 2014). We conclude that the jordan variant does not affect folding, whilst the shaker-2 caused misfolding, consistent with the mutation being within the ATPase transducer core (Gong et al., 2021).

To test for differences in enzymatic activity between wild-type and jordan motor domain variants (Fig. 5A), we measured steady-state ATP hydrolysis using an enzyme-linked NADH assay. The basal ATPase activity ( $k_{\text {basal }}$ ) of the wild-type motor domain was $0.06 \pm 0.01 \mathrm{~s}^{-1}$, measured without F-actin. The addition of F-actin caused a 97-fold increase in ATPase activity to an extrapolated maximum catalytic rate $\left(k_{\text {cat }}\right)$ of $5.8 \pm 0.2 \mathrm{~s}^{-1}$ (Fig. 5D). Half-maximal activation of the ATPase activity (KATPase) was reached at $29.1 \pm 2.1 \mu \mathrm{M}$ F-actin, as previously reported (Bird et al., 2014; Jiang et al., 2021). Using identical assay conditions, the basal ATPase rate of the jordan variant was unchanged at $k_{\text {basal }}=0.07 \pm 0.01 \mathrm{~s}^{-1}$. Strikingly, there was a reduced 7 -fold maximal activation to $k_{\text {cat }}=0.87 \pm 0.04 \mathrm{~s}^{-1}$ (Fig. 5D). Furthermore, half-maximal ATPase activation was increased to $K_{\text {ATPase }}=114.3 \pm 8.2 \mu \mathrm{M}$ actin, signifying a 4-fold reduction in the apparent actin affinity compared to wild-type.

The mechanical activity of wild-type and jordan motor domains was measured using an in vitro the jordan motor domain for actin, we lowered the salt concentration to $10 \mathrm{mM} \mathrm{KCl}$ in these assays. The wild-type motor domain robustly propelled actin filaments at $473 \pm 67 \mathrm{~nm} \cdot \mathrm{s}^{-1}$ (Fig. 5E), consistent with previous data (Bird et al., 2014). In contrast, the jordan mutant moved filaments at $216 \pm 71 \mathrm{~nm} \cdot \mathrm{s}^{-}$ 1, a 2-fold reduction from the wild-type velocity (Fig. 5E). Overall, we conclude that whilst the jordan mutation caused a significant ATPase defect and decreased the motor domain's apparent affinity for actin, the motor domain was still mechanically active. Our data further establish a functional correlation between motor domain activity and the severity of hearing loss in a Myo15 allelic series. The jordan motor domain retained partial activity consistent with this mutation causing intermediate hearing loss, whilst the shaker-2 motor domain was misfolded and associated with the most severe phenotype.

\section{The MY015 motor domain directly stimulates actin polymerization}

Our in vitro analysis of purified MYO15 motor activities were consistent with the jordan mutant maintaining the ability to traffic the elongation complex and accumulate at stereocilia tips. As 
stereocilia nevertheless fail to grow normally in jordan hair cells, we hypothesized that independent of molecular trafficking, MYO15 had an additional function at the stereocilia tip critical for elongation. Classic biochemical studies of muscle myosin have shown its motor domain (e.g. subfragment-1, S1) can directly stimulate actin polymerization in vitro; however, the physiological relevance of this activity in vivo, if any, is unknown (Yagi et al., 1965; Miller et al., 1988; Fievez and Carlier, 1993; Lheureux et al., 1993). We hypothesized that the MYO15 motor domain could directly stimulate actin polymerization to drive stereocilia elongation, and that this critical activity is disrupted by the jordan deafness mutation.

We tested this hypothesis using pyrene-conjugated globular actin (G-actin) monomers that increase in fluorescence as they polymerize into filamentous actin (F-actin) (Cooper et al., 1983). As a control, $2 \mu \mathrm{M}$ G-actin was polymerized with 1x KMEl $(50 \mathrm{mM} \mathrm{KCl}, 1 \mathrm{mM} \mathrm{MgCl}$, 1 mM EGTA, $10 \mathrm{mM}$ imidazole) while monitoring pyrene fluorescence. F-actin assembled with an initial lag phase representing the kinetically unfavourable nucleation step (Fig. 6A, red line). When the reaction was repeated with $1 \mu \mathrm{M}$ wild-type motor domain + $2 \mu \mathrm{M}$ G-actin + KMEI, actin polymerization initially followed the same trajectory (Fig. 6A, blue line). However, following a delay of $\sim 400$ seconds, an inflection was observed where the rate of actin polymerization reduced momentarily (Fig. 6A, blue line), before rapidly increasing and reaching steady-state (Fig. 6A,B). We tested if MYO15-stimulated actin polymerization was sensitive to the jordan mutation. Under identical experimental conditions using $1 \mu \mathrm{M}$ jordan MYO15 motor domain, the actin polymerization rate was initially indistinguishable from the control reaction. However, following an inflection at $\sim 600$ seconds, the actin polymerization rate decreased below that of the G-actin alone control (Fig. 6A). We conclude that the wild-type MYO15 motor domain stimulated actin polymerization, whilst the deafness-causing jordan mutant blocked this activity.

With either wild-type or jordan motor domains, we observed a delay before the actin polymerization rate deviated from the control, with the delay longer for jordan ( 600s) versus wildtype ( 400s). We hypothesized this difference arose from residual ATP $(70 \mu \mathrm{M})$ being introduced 343 from the G-actin storage buffer; ATP binding would prevent the motor domain from occupying the 344 strongly actin bound (rigor) state. Furthermore, we expected this residual ATP to be hydrolysed faster 345 by the wild-type motor domain, compared with the jordan mutant (Fig. 5D). To test this, we repeated 346 the pyrene polymerization assay in the absence of free ATP. To ensure G-actin monomers were ATP347 bound, G-actin was desalted immediately prior to use to remove free ATP from solution. Using this 348 approach, we measured the polymerization of $2 \mu \mathrm{M}$ G-actin $+\mathrm{KMEl}$ in the absence of free ATP (Fig. 
6C) and observed kinetics comparable to before (Fig. 6A). Strikingly, pyrene fluorescence immediately increased upon addition of $1 \mu \mathrm{M}$ wild-type motor to the reaction, and rapidly saturated (Fig. 6C) with a significantly reduced half-time of $124 \pm 12 \mathrm{~s}$, compared with $1091 \pm 202 \mathrm{~s}$ for G-actin + KMEl alone (Fig. 6D). While addition of $1 \mu \mathrm{M}$ jordan motor domain to $2 \mu \mathrm{M}$ G-actin $+\mathrm{KMEl}$ reduced the overall extent of actin polymerization (Fig. 6C), the half-time to saturation was $1000 \pm 65 \mathrm{~s}$ and not significantly different to G-actin + KMEI alone (Fig. 6D). We conclude that the wild-type MYO15 motor domain strongly accelerated actin filament polymerization in the absence of ATP, implicating the rigor state as critical for this activity. Combined with experiments from our companion study showing that ADP-bound MYO15 also stimulated polymerization (Gong et al., 2021), these data identify the strong actin-binding states as the key MYO15 ATPase intermediates that stimulate actin polymerization.

\section{The jordan deafness mutation inhibits de novo nucleation of actin filaments}

To directly visualize how the MYO15 motor domain accelerates polymerization, we performed actin polymerization assays using total internal reflection fluorescence microscopy (TIRFM) where the elongation of individual filaments can be tracked (Fujiwara et al., 2002). A control time-lapse of $1 \mu \mathrm{M}$ G-actin + KMEI revealed a slow rate of filament nucleation, with short polymers attaching to surface and elongating (Fig. 7A, top row). We repeated the experiment with $1 \mu \mathrm{M}$ wild-type motor domain and observed a large burst in filament density (Fig. 7A, middle row) that was statistically significant at 480 seconds when compared to the actin-alone control (Fig. 7B). In contrast, when polymerization experiments were repeated with $1 \mu \mathrm{M}$ jordan motor domain (Fig. 7A, bottom row), there was no increase in actin filament density above the actin-alone control (Fig. 7C). Using kymographs to track filament barbed ends, we found that the motor domain could influence actin filament elongation rates. In control experiments, barbed ends elongated at $16.2 \pm 2.6 \mathrm{~nm} \cdot \mathrm{s}^{-1}$ (Fig. 7C,D), consistent with previous data using TMR-conjugated G-actin on Cys374 (Kuhn and Pollard, 2005). Elongation rates were significantly reduced by the addition of either wild-type or jordan motor domain, to $13.3 \pm 4.3$ $\mathrm{nm} \cdot \mathrm{s}^{-1}$ and $13.4 \pm 3.5 \mathrm{~nm} \cdot \mathrm{s}^{-1}$, respectively (Fig. 7C,D). The decrease in elongation rate was dependent upon timing of the filament burst (Fig. 7B). When data were binned as pre-burst $(<320 \mathrm{~s})$, the addition of wild-type or jordan motor domains did not significantly alter elongation rates compared to the control (Fig. 7E). In contrast, the presence of either wild-type or jordan motor domain post-burst (>720 s) both significantly, and equally, reduced elongation rates below the actin alone control (Fig. 7F).

Nucleation by wild-type MYO15 took an average of 480 seconds to be significantly increased above the spontaneous nucleation rate of G-actin + KMEl alone (Fig. 7B). We considered whether the delayed production of short filaments was caused by MYO15 severing actin filaments that nucleated 
spontaneously. To test this hypothesis, we repeated our experiments in the absence of free ATP to force the motor domain into rigor binding and accelerate polymerization. Free ATP was desalted from $1 \mu \mathrm{M}$ G-actin monomers; this did not affect barbed-end elongated rates when polymerized by $\mathrm{KMEI}$ (Fig. 7D,I). As expected, when $1 \mu \mathrm{M}$ wild-type motor domain was included in the reaction, there was a potent nucleation of short actin filaments observed within $90 \mathrm{~s}$ (Fig. 7G,H), confirming acceleration of nucleation when the motor domain was forced into rigor. Under identical ATP free conditions, $1 \mu \mathrm{M}$ jordan motor domain did not nucleate additional filaments compared with the G-actin + KMEl control (Fig. 7G,H). Similar to experiments where ATP was present, but presumably hydrolyzed (Fig. 7F, > $720 \mathrm{~s}$ ), we saw that both wild-type and jordan motor domains significantly reduced barbed-end elongation rates (Fig. 7I). We conclude that the MYO15 motor domain exerts multiple direct effects on actin polymerization, including catalyzing de novo filament nucleation and reducing barbed end elongation rates in a nucleotide-dependent fashion. Our data show that MYO15-induced actin nucleation is a key process targeted by the jordan deafness mutation, and argue that this activity is critical for stereocilia elongation and hearing.

\section{DISCUSSION}

Plasticity of the stereocilia actin core is central to hair bundle development, mechanosensitivity and hearing. Existing evidence that MYO15 moves along stereocilia actin filaments has led to a cargo trafficking model, where the elongation complex is delivered to the stereocilia tips and provides the actin regulation machinery necessary for elongation. Here, we uncover a previously unknown activity of MYO15 that requires the cargo-trafficking model to be re-evaluated. In vitro, we show that MYO15 can directly stimulate actin filament nucleation and that this activity is inhibited by the jordan mutation, providing key evidence this activity is functionally linked to deafness pathology. In vivo, the Myo15 jordan mutation stunted stereocilia growth, leading to an early-onset, progressive hearing loss in mice. The effect of the jordan mutation to inhibit MYO15-induced actin nucleation in vitro, and block stereocilia elongation in vivo, provides the functional link between these two processes. We propose that in addition to trafficking key molecular cargos, MYO15 directly catalyses actin filament nucleation at the stereocilia tip, and that both these processes combined are required for normal stereocilia growth.

Using purified proteins and reconstituted assays, the MYO15 motor domain exerted multiple effects upon actin filament polymerization in vitro. The motor domain: 1) nucleated actin filaments de novo, and 2) slowed the elongation rate of existing actin filaments. No additional proteins were required, demonstrating that these properties were intrinsic to the purified actomyosin system. The 
417 jordan mutation completely blocked MYO15-induced actin filament nucleation, whilst filament

418 elongation rates were unaffected relative to wild-type MY015. We conclude that MYO15's nucleation

419 activity is the key polymerization effect disrupted by the jordan deafness mutation. Similar to MYO15,

420 muscle myosin was shown in classic biochemical experiments to stimulate actin filament nucleation in

421 vitro (Yagi et al., 1965; Miller et al., 1988; Fievez and Carlier, 1993; Lheureux et al., 1993). The

422 MYO15 motor domain shares a common structural fold with muscle myosin (Gong et al., 2021), and

423 although the mechanism of muscle nucleation remains controversial (Lheureux et al., 1993), we

424 believe by homology to muscle that MYO15 nucleates actin through stabilizing inter-subunit contacts

425 that establish the protofilament (Fievez et al., 1997a, 1997b). In our companion study (Gong et al.,

426 2021), the MYO15 motor domain is further shown to influence structural plasticity within the DNasel-

427 binding loop (D-loop), a sub-domain of actin that regulates the monomer to polymer transition

428 (Dominguez and Holmes, 2011). Combined, our data argue that nucleation is a shared function for at

429 least some members of the myosin superfamily, and that myosin motors can directly influence

430 cytoskeletal plasticity in addition to their canonical role generating force.

431

A cellular function for myosin-driven actin nucleation has, to the best of our knowledge, not previously been reported in any tissue. Our study provides evidence that MYO15-driven nucleation contributes to hair cell function in vivo, and furthermore is a cause of disease when disrupted. Actin nucleation by MYO15 appears distinct from other nucleation factors, such as formins, Arp2/3, Spire and Cobl (Machesky et al., 1994; Mullins et al., 1997, 1998; Sagot et al., 2002; Quinlan et al., 2005; Ahuja et al., 2007). MYO15-driven nucleation was nucleotide-sensitive, and strongly promoted nucleation under rigor (nucleotide-free) conditions, or when bound to ADP (Gong et al., 2021). Both conditions populate the motor domain into strong actin binding states (Jiang et al., 2021). Conversely, the presence of ATP in assays prevented nucleation and we hypothesize this is due to the motor domain populating a weakly actin-bound state (Jiang et al., 2021). The nucleotide-sensing properties of MYO15 may therefore couple local concentrations of ATP and ADP to actin polymerization. We speculate this activity could form the basis of a tuning mechanism, where dynamic changes in nucleotide concentrations control the height of developing stereocilia. The concentrations of ATP and ADP in stereocilia are unknown, and whilst a creatine kinase ATP generation system has been described in avian hair cells (Shin et al., 2007), its activity in mammals is unclear (Krey and BarrGillespie, 2019). In addition to nucleotide state, MYO15-driven nucleation in vitro was observed at high protein concentrations equimolar with actin, in agreement with data from muscle myosin (Miller et al., 1988). The concentration of MYO15 in hair cells is unknown, however micromolar quantities may be present at the stereocilia tips, especially as MYO15 actively traffics and self concentrates into this 
subcellular compartment (Belyantseva et al., 2003). Other unconventional myosin motors critical for hearing, including MYO1C, MYO3A, MYO6 and MYO7A (Avraham et al., 1995; Gibson et al., 1995; Gillespie and Corey, 1997; Hasson et al., 1997; Holt et al., 2002; Salles et al., 2009; Ebrahim et al., 2016), also concentrate in specific stereocilia sub-domains and it is exciting to consider whether they also directly regulate actin polymerization as part of their cellular function.

In parallel with identifying MYO15 as an actin nucleator, we used the jordan mutant mouse to probe sufficiency of the elongation complex to drive stereocilia elongation. Each protein in the elongation complex is critical for growth, but existing models do not explain their molecular activty, except that they must be delivered to the stereocilia tip via MYO15-driven trafficking. This model is based on the shaker-2 mouse, where stereocilia growth is inhibited and both MYO15 and the elongation complex are absent from the hair bundle (Belyantseva et al., 2005; Delprat et al., 2005; Manor et al., 2011; Zampini et al., 2011; Mauriac et al., 2017; Tadenev et al., 2019). Our data show that MYO15-driven actin nucleation and elongation complex trafficking activities are simultaneously lost in the shaker-2, leaving their relative contributions unknown. By contrast, MYO15-driven trafficking of the elongation complex is initially (largely) preserved in the short stereocilia of the jordan mouse. These data argue that the elongation complex proteins are necessary, but not sufficient for driving stereocilia growth, and that MY015-nucleation activity is critical in vivo. We cannot exclude the possibility of reduced MYO15 trafficking in jordan hair cells; indeed, gliding filament velocities of the mutant motor were $\sim 50 \%$ of the wild-type in vitro. However, there is no evidence that the concentration of MYO15 at the stereocilia tips determines stereocilia length. Neither the elimination of MY015-1 from shorter stereocilia rows (Fang et al., 2015), nor the over-expression of MYO15-2 alters initial stereocilia lengths (Belyantseva et al., 2003, 2005). We also considered whether the jordan mutation might interfere with MYO15 binding to another protein critical for stereocilia growth. Our companion study (Gong et al., 2021) localizes the jordan missense substitution to the actomyosin interface, and shows a direct structural effect within the actin monomer itself. Combined with our study, these findings strongly suggest that MYO15 directly accelerates actin nucleation at the stereocilia tip by structurally regulating the actin molecule. cytoskeleton, processes that must be tightly controlled for mechano-transduction and lifelong hearing 482 (Vélez-Ortega and Frolenkov, 2019). Stereocilia actin filaments are unidirectionally polarized with their 483 fast-growing barbed ends orientated towards the tip compartment, where new actin monomers are incorporated (Flock and Cheung, 1977; Tilney et al., 1980; Schneider et al., 2002; Drummond et al., 
2015). Although actin capping proteins also contribute to stereocilia architecture (Peng et al., 2009; Avenarius et al., 2017), we find that excessive barbed end capping is not the cause of short stereocilia in Myo15 mutant mice. Given the presence of barbed ends, why might actin nucleation be required to extend pre-existing filaments at stereocilia tips? One possible explanation is that stereocilia elongation occurs through direct end-to-end annealing of short actin polymers nucleated by MYO15, rather than through addition of individual actin monomers at the barbed end. Pre-formed actin filaments can anneal into longer filaments in vitro (Murphy et al., 1988; Kinosian et al., 1993; Sept et al., 1999), and more recent in vitro studies have detected filament extension through incorporation of short polymers, in addition to the dominant mode of monomer addition (Young et al., 2018). Interestingly, endocytosis in yeast is proposed to use end-to-end actin filament annealing rather than monomer polymerization (Okreglak and Drubin, 2010). Though speculative in hair cells, the extension of the stereocilia actin core using short polymer annealing may allow for rapid changes in stereocilia length that are likely needed to continually maintain the sensitivity of the MET machinery (Vélez-Ortega et al., 2017; Krey et al., 2020).

Given the potent ability of MYO15 to nucleate actin filament polymerization in vitro, we infer this activity must be tightly regulated in hair cells. There is extensive evidence for intramolecular regulation throughout the myosin superfamily (Heissler and Sellers, 2016). For example, myosin 5 (MYO5A) exists in an autoinhibited conformer where the globular tail domain binds and inhibits motor domain activity; binding of melanophilin (MLPH) to MYO5 releases this autoinhibition to activate the motor domain (Li et al., 2005; Liu et al., 2006; Thirumurugan et al., 2006; Sato et al., 2007; Sckolnick et al., 2013). Similar autoinhibitory regulation mechanisms have been described for other members of the MyTH4 - FERM myosin family, e.g., MYO7A and MYO10 (Umeki et al., 2009, 2011; Yang et al., 2009; Sakai et al., 2011). We hypothesize that part of the elongation complex function may be to bind MYO15 and shift the equilibrium between active and inhibited states. Intramolecular regulation may also explain how different MYO15 isoforms independently exert their effects upon hair bundle architecture (Fang et al., 2015). MYO15-1 and MY015-2 possess an identical motor domain competent to regulate actin polymerization, but differ by the addition of a $133 \mathrm{kDa} \mathrm{N}$-terminal domain (Fig. 1A). How the N-terminal domain affects the actin nucleation activity of the motor domain is an important future question and will help uncover how the MY015-1 isoform controls actin polymerization in shorter stereocilia rows with active MET (Fang et al., 2015). In conclusion, we reveal a new function for MYO15 and argue that defective nucleation of actin polymerization interferes with stereocilia architecture and causes progressive hearing loss. We speculate that defective actin 
518 nucleation by MYO15 is a central molecular pathology underlying DFNB3 hereditary hearing loss in 519 humans.

\section{MATERIALS AND METHODS}

522 Mice

Pedigree MPC190 was identified from a phenotype-driven mutagenesis screen undertaken at 524 the MRC Harwell Institute (Potter et al., 2016). Briefly, $N$-ethyl- $N$-nitrosourea (ENU) mutagenized $525 \mathrm{C} 57 \mathrm{BL} / 6 \mathrm{~J}$ males were mated with wild-type 'sighted $\mathrm{C} 3 \mathrm{H}^{\prime}\left(\mathrm{C} 3 \mathrm{H} . \mathrm{Pde} \mathrm{b}^{+}\right)$females. Resulting $\mathrm{G}_{1}$ males 526 were crossed with $\mathrm{C} 3 \mathrm{H} . P d e 6 \mathrm{~b}^{+}$females to produce $\mathrm{G}_{2}$ females, which were screened for the $\mathrm{Cdh} 23^{\text {ahl }}$ 527 allele. Cdh $23^{+/+} \mathrm{G}_{2}$ females were backcrossed to their $\mathrm{G}_{1}$ fathers to generate recessive $\mathrm{G}_{3}$ pedigrees, 528 which entered a longitudinal phenotyping pipeline that included click box and ABR tests to assess 529 auditory function (Hardisty-Hughes et al., 2010). DNA from mice exhibiting hearing loss, and normal 530 hearing pedigree mates, was prepared from ear biopsies and used for linkage mapping utilizing the Illumina GoldenGate Mouse Medium Density Linkage Panel (Gen-Probe Life Sciences Ltd, UK), which identified a critical interval on chromosome 11. DNA was extracted from mouse MPC190/2.18a and subject to whole genome sequencing employing the Illumina HiSeq platform (Oxford Genomics Centre, Wellcome Trust Centre for Human Genetics). Subsequent alignment to the reference genome (NCBIM38/mm10) identified a homozygous, non-synonymous coding lesion in the Myo15 gene. under conditions outlined in the Home Office Code of Practice, with all animal procedures licenced by the Home Office under the Animals (Scientific Procedures) Act 1986, UK and approved by the local Ethical Review Committee (PBF9BD884 to MRB). At MRC Harwell, jordan mice were crossed to C57BL/6N (Cdh23 $\left.{ }^{753 A>G}\right)$ 'repaired' mice (Mianné et al., 2016) until congenic. Concurrently, jordan

542 mice were imported to the NIH and the University of Florida (UF) and maintained on a 'sightless C3H' 543 (C3H.Pde6 $\left.\mathrm{b}^{\text {rd1 }}\right)$ background. Animal procedures were approved the Institutional Animal Care and Use 544 Committees (IACUC) at UF (\#201910739 to JEB) and at the NIH (\#1263-15 to TBF). Genomic DNA 545 from mouse tail biopsies was used as template in a PCR reaction with primers (5'-

546 CAGGAGGAGTACATCCGGG-3', 5'-AGACCACAGAAGTATCTGGGTCTT-3'). The resulting 161 bp 547 amplicon was analyzed by $M / s /$ endonuclease digestion. Resulting restriction fragments lengths 548 unambiguously detected wild-type (161 bp) and mutant (116 bp + $45 \mathrm{bp}$ ) alleles.

\section{Auditory phenotyping + behavioral testing}


Auditory Brainstem Response (ABR) were recorded as previously described (Dunbar et al., 2019). Briefly, mice were anaesthetised via intraperitoneal injection with ketamine hydrochloride (100 $\left.\mathrm{mg} \cdot \mathrm{kg}^{-1}\right)$ and xylazine $\left(10 \mathrm{mg} \cdot \mathrm{kg}^{-1}\right)$. Anesthetized mice were placed inside a sound-attenuated chamber (ETS-Lindgren) and recording electrodes (Grass Telefactor F-E2-12) placed sub dermally over the vertex (active), right mastoid (reference), and left flank (ground). ABR responses were collected using TDT system III hardware and BioSig software (Tucker Davis Technology). Stimuli were presented free field from a ES1 transducer (TDT) calibrated at a distance of $1 \mathrm{~cm}$ from the right ear.

Stimuli consisted of $0.1 \mathrm{~ms}$ broadband clicks or $7 \mathrm{~ms}$ tone-bursts at $8 \mathrm{kHz}, 16 \mathrm{kHz}$ and $32 \mathrm{kHz}$. Each stimulus was presented at a maximum $90 \mathrm{~dB}$ SPL, followed by decreasing steps of 5 - $10 \mathrm{~dB}$ SPL until no replicable response peaks were observed. ABR operators were blind to genotype. 12 weeks old mice, as described (Dunbar et al., 2019). Mice were anaesthetised with a modified ketamine/xylazine solution (see ABR), with the addition of acepromazine $\left(2 \mathrm{mg} \cdot \mathrm{ml}^{-1}, 8 \% \mathrm{v} / \mathrm{v}\right)$. Anesthetized mice had a section of the pinna removed to access the external auditory meatus. Mice were placed inside a sound-attenuated chamber (ETS Lindgren), and the DPOAE probe assembly was inserted into the ear canal. In-ear calibration was performed before each test. An ER10B+ lownoise probe microphone (Etymotic Research) was used to measure DPOAEs near the tympanic membrane. Tone stimuli were presented via separate MF1 (Tucker Davis Technology) speakers, with $\mathrm{f} 1$ and $\mathrm{f} 2$ at a ratio of $\mathrm{f} 2 / \mathrm{f} 1=1.2(\mathrm{~L} 1=65 \mathrm{~dB}$ SPL, $\mathrm{L} 2=55 \mathrm{~dB}$ SPL). The $\mathrm{f} 1$ and $\mathrm{f} 2$ tones were presented continuously in specific tone-bursts between 8 and $32 \mathrm{kHz}$.

572

\section{Scanning electron microscopy}

574

Inner ears were dissected and fixed overnight at $4^{\circ} \mathrm{C}$ in $0.1 \mathrm{M}$ phosphate buffer, $2.5 \%$ glutaraldehyde (Sigma-Aldrich). Post-fixed ears were decalcified in 4.3\% EDTA in phosphate buffer at $4^{\circ} \mathrm{C}$, before dissecting out the sensory epithelium. Samples were processed with alternating $1 \%$ osmium tetroxide (Agar Scientific) in $0.1 \mathrm{M}$ sodium cacodylate (Sigma-Aldrich) and $1 \%$ thiocarbohydrazide (Sigma-Aldrich) treatments. Osmicated samples were dehydrated in graded ethanols (25\% to $100 \%)$ at $4^{\circ} \mathrm{C}$ and stored in $100 \%$ acetone until critical point drying with liquid $\mathrm{CO}_{2}$ 580 (EM CPD300, Leica Microsystems Ltd.). Samples were mounted onto stubs using silver paint (Agar 581 Scientific), sputter-coated with platinum (Q150R S, Quorum Technologies) and visualised with a 582 scanning electron microscope (JSM-6010LV, JEOL). 

were captured with a $5^{\circ}$ tilt angle difference at a constant working distance of $20 \mu \mathrm{m}$. Stereocilia from at least two bundles per animal were measured using ImageJ (https://imagej.nih.gov), with a minimum of 14 stereocilia for each condition. Length measurements were taken from the rear aspect of the hair bundle, so that the length of the tallest stereocilia (row 1) could be measured from the cuticular plate insertion to the tip. Estimates for actual stereocilia length were calculated using a pseudo-eucentric tilting approach (Bariani et al., 2005). A single measure $x_{1}$ (length of stereocilium) was taken from the first image and measured again $\left(x_{2}\right)$ on the corresponding $5^{\circ}$-tilted image pair. Perpendicular countermeasures $\left(\mathrm{y}_{1}\right.$ and $\left.\mathrm{y}_{2}\right)$, matched to $\left(\mathrm{x}_{1}\right.$ and $\left.\mathrm{x}_{2}\right)$ were also recorded. Equation 1 was used to estimate uncertainty $(\zeta)$ due to plane rotation. Using the uncertainty estimate $\zeta$ from Equation 1, every pair of tilted measures $\left(x_{1}\right.$ and $\left.x_{2}\right)$ was processed using Equation 2 to obtain a close approximation ( $\xi$ ) of the true length of each stereocilia measured.

Where: $\zeta=$ uncertainty estimate, $\xi=$ estimate of true size of structure of interest, $x_{1,2}=$ tilted paired-measures of structure of interest, $\mathrm{y}_{1,2}=$ perpendicular counter-measures to measures $\mathrm{x}_{1,2}, \Delta \mathrm{y}=$ arithmetic difference of counter-measures $\mathrm{y}_{1}$ and $\mathrm{y}_{2}, \Delta \varphi=$ tilting angle $\left(5^{\circ}\right), d=$ working distance $(20$ $\mu \mathrm{m})$.

605

606

In addition, low-magnification (1500 - 2000X) fields of mid-turn sensory epithelium were imaged and the $\mathrm{OHC}$ bundles counted and visually categorised as either: 'Intact', 'Abnormal / Damaged' where the bundle had an abnormal shape or was missing stereocilia, or 'Missing Bundle' where a cuticular plate was observed with no stereocilia. Cochleae from four different animals per genotype were examined, with a total of 1344 wild type and 972 jordan $\mathrm{OHC}$ bundles.

\section{Whole mount immunofluorescence and confocal microscopy} room temperature, washed in PBS, and then micro-dissected to isolate the cochlear sensory epithelium. Samples were permeabilized in 0.5\% (v/v) Triton X-100 in PBS for 30 minutes at RT, 
617 Roche) in PBS for 1 hour at RT. Primary antibodies were diluted in blocking solution and incubated 618 with samples at $4^{\circ} \mathrm{C}$ overnight. Primary lgG antibodies used were: PB48 rabbit anti-MYO15 (Liang et 619 al., 1999), HL5136 rabbit anti-WHRN (Belyantseva et al., 2005), mouse anti-EPS8 (\#610143, BD 620 Biosciences), rabbit anti-GPSM2 (Ezan et al., 2013) and rabbit anti-GNAI3 (\#G4040, Sigma-Aldrich). 621 After washing in PBS, samples were labelled with Alexa Fluor 488 conjugated anti-lgG secondary 622 antibodies (Life Technologies) diluted in blocking solution for 1 hour at RT. Samples were co-labelled 623 with rhodamine phalloidin (Life Technologies) and mounted with high-precision \#1.5 cover glass 624 (Zeiss) using Prolong Gold (Life Technologies). Images were captured using a 63x objective (1.4 NA, 625 plan apochromat, Zeiss) and a laser scanning confocal microscope (LSM780, Zeiss).

\section{Actin barbed end incorporation assay}

Cochleae from shaker-2 or jordan mice were dissected at P6 in Leibowitz L-15 media (Life Technologies) and adhered to the inside surface of a petri dish lid (Greiner CellStar $35 \times 10 \mathrm{~mm}$ ). The stria vascularis was left intact, as described (Xiong et al., 2014). Cochleae were cultured for 6 hours in DMEM / F-12 (Life Technologies) supplemented with 1\% FBS (Atlanta Biologicals) and $1.5 \mu \mathrm{g} \cdot \mathrm{mL}^{-1}$ ampicillin at $37^{\circ} \mathrm{C}, 5 \% \mathrm{CO}_{2}$. Cochlea were incubated for 2 minutes at $\mathrm{RT}$ in $0.5 \mu \mathrm{M}$ TMR-actin (Cytoskeleton) diluted in labelling buffer (concentrations in mM): HEPES (20), KCl (138), EGTA (3), $\mathrm{MgCl}_{2}$ (4), ATP (1), DTT (0.5), 1\% (w/v) bovine serum albumin (BSA), $0.2 \mathrm{mg} \cdot \mathrm{mL}^{-1}$ saponin, $\mathrm{pH} 7.5$. Cochleae were immediately fixed for 30 mins at RT in 4\% paraformaldehyde (EMS Diasum) diluted in PHEM buffer (concentrations in mM): PIPES (60), HEPES (25), EGTA (10), $\mathrm{MgCl}_{2}$ (2), sucrose (120), $\mathrm{pH}$ 7.0. Fixed cochleae were permeabilized in $0.5 \%(\mathrm{v} / \mathrm{v})$ Triton X-100 in PBS for 30 minutes at RT, labelled with Alexa 488 phalloidin (Life Technologies), and mounted using a high-precision \#1.5 cover glass (Zeiss) with Prolong Gold (Life Technologies). Confocal microscopy images were captured as described above.

\section{Expression of EGFP-MYO15-2 in mammalian cells}

The pEGFP-C2-Myo15-2 and pEGFP-C2-Myo15-2(sh2) plasmids expressing an N-terminal EGFP fusion with the mouse MYO15 isoform 2 coding sequence (NP_874357.2) were previously reported (Belyantseva et al., 2003). The pEGFP-C2-Myo15-2(jd) plasmid was generated using site directed mutagenesis (QuikChange II, Agilent) to introduce the jordan (c.4940A>G) non-synonymous substitution. All expression plasmids were verified by Sanger sequencing and prepared as endotoxinfree, transfection grade DNA (NucleoBond Xtra Maxi EF, TakaraBio). HeLa cells (\#CCL2) were obtained as an authenticated, low passage stock from the American Type Culture Collection (ATCC). 
651 and CL4 cells were cultured in high-glucose DMEM (\#11995, Life Technologies), supplemented with

652 1x GlutaMAX (Life Technologies) and 10\% FBS (Atlanta Biologicals), and maintained at $37^{\circ} \mathrm{C}, 5 \%$

$653 \mathrm{CO}_{2}$. Transfection of HeLa cells or CL4 cells was performed using Lipofectamine 3000 (Life

654 Technologies) according to the manufacturer's protocol. pEGFP-C2 (Clontech) was used as an empty 655 vector control. Cells were plated onto fibronectin $\left(10 \mu \mathrm{g} \cdot \mathrm{mL}^{-1}\right)$ coated glass bottom culture dishes 656 (\#1.5, MatTek Corp) and allowed to adhere, and in the case of CL4 cells, characteristic island 657 formation could be observed. Cells were fixed in 4\% paraformaldehyde and $2 \%$ sucrose in PBS for 10 $658 \mathrm{mins}$ (EMS Diasum). Fixed cells were permeabilized/blocked in 0.2\% (v/v) Triton X-100, 10\% (v/v) 659 normal goat serum (NGS) in PBS for $1 \mathrm{hr}$ at RT, followed by labelling with rhodamine phalloidin (Life 660 Technologies) and Hoechst 33342 (Life Technologies) in blocking buffer (2\% NGS in PBS). Confocal 661 microscopy images were captured as described above.

662

663

664

\section{Actin purification and labelling}

Actin was extracted from rabbit skeletal acetone powder (Pel-Freeze, AZ) in chilled G-buffer (concentrations in mM), Tris- $\mathrm{HCl}(2), \operatorname{ATP}(0.2), \mathrm{CaCl}_{2}(0.1), \mathrm{NaN}_{3}$ (1), DTT (1), pH 8, using established protocols (Spudich and Watt, 1971). Actin was additionally labelled on Cys 374 using either N-(1-pyrene)-iodoacetamide (Life Technologies), or tetramethylrhodamine-5-maleimide (Adipogen Life Sciences)(Criddle et al., 1985; Fujiwara et al., 2002). F-actin used for steady-state ATPase and gliding filaments assays was purified through two rounds of polymerization and depolymerization using ultracentrifugation. F-actin was dialyzed extensively against MOPS (4), $\mathrm{MgCl}_{2}$ (1), EGTA (0.1), DTT (1), $\mathrm{NaN}_{3}$ (1), pH 7.0, and its concentration measured at $290 \mathrm{~nm}\left(\varepsilon=26,600 \mathrm{M}^{-}\right.$ ${ }^{1} \cdot \mathrm{cm}^{-1}$ ) prior to use. Unlabelled, pyrene- and TMR-labelled G-actin for polymerization studies were 673 further purified by size exclusion chromatography (Superdex 200, Cytiva) using isocratic elution in Gbuffer. Fractions were exclusively taken from the falling edge of the chromatogram, to ensure the recovery of monomeric actin. Concentrations and dye-labelling efficiency was determined at $290 \mathrm{~nm}$ (actin: $\varepsilon=26,600 \mathrm{M}^{-1} \cdot \mathrm{cm}^{-1}$ ), $344 \mathrm{~nm}$ (pyrene: $\varepsilon=22,000 \mathrm{M}^{-1} \cdot \mathrm{cm}^{-1}$ ) and $550 \mathrm{~nm}$ (rhodamine: $\varepsilon=96,900$ $\left.\mathrm{M}^{-1} \cdot \mathrm{cm}^{-1}\right)$. Correction factors were applied for pyrene actin, $A_{\text {corr }}=A_{290}-\left(0.127{ }^{*} A_{344}\right)$, and separately for rhodamine actin, $A_{c o r r}=A_{290}-\left(0.208 * A_{550}\right)$ (Fujiwara et al., 2002). Biotinylated skeletal muscle actin (\#8109-01, HyperMol, Germany) was rehydrated, dialyzed against G-buffer and cleared by ultracentrifugation for 60 minutes at $100 \mathrm{k} \times g$ prior to use. For actin polymerization experiments performed without free ATP in solution, G-actin stocks (with $0.2 \mathrm{mM} \mathrm{ATP)}$ were desalted (PD 682 SpinTrap G-25, Cytiva) into a modified G-buffer (no ATP): Tris- $\mathrm{HCl}$ (2), $\mathrm{CaCl}_{2}(0.1), \mathrm{NaN}_{3}$ (1), DTT (1), $683 \mathrm{pH} 8$, immediately prior to use. Desalted G-actin (ATP) monomers were stored on ice and used within 6843 hours. 


\section{Expression of MYO15 and deafness mutants in Sf9 cells using baculovirus}

The baculoviral transfer vector pFastbac1 M15-2IQ-EGFP-FLAG, encoding the wild-type mouse MYO15 motor domain (NP_874357.2, aa. 1 - 743) as a C-terminal fusion with EGFP and FLAG moieties, was previously described (Bird et al., 2014). The expressed protein was $114 \mathrm{kDa}$. The jordan and shaker-2 non-synonymous substitutions were separately introduced into pFastbac1 M15sequencing. Plasmid DNA encoding wild-type, jordan and shaker-2 was separately transformed into DH10Bac cells (Life Technologies) and recombinant bacmid DNA prepared following the manufacturer's protocol. First passage (P1) recombinant baculovirus was generated by transfecting Sf9 cells (Expression Systems) with bacmid DNA complexed using linear polyethylenimine (PEI MAX, 40,000 MW, Polysciences Inc., PA) at a 12:1 (PEI : DNA) molar ratio. Sf9 cells were maintained in suspension culture with ESF-921 medium (Expression Systems) in a shaking incubator at $27^{\circ} \mathrm{C}$. P1 baculovirus was amplified in Sf9 cells using low multiplicity of infection $(\mathrm{MOI}=0.1)$ to generate P2 baculovirus for expression. Dual-promoter baculovirus expressing mouse UNC45B + HSP90AA1 chaperones (Bird et al., 2014), and bovine smooth muscle essential (MYL6, also referred to as MLC17B / ELC) + chicken regulatory (MYL12B, also referred to as MLC20 / RLC ) light chains, were previously described (Pato et al., 1996). All baculoviruses were tittered using an end-point dilution assay and the Sf9 Easy Titer cell line (Hopkins and Esposito, 2009). To express M15-2IQ, Sf9 cells were seeded at a density of $2 \times 10^{6}$ cells $\cdot \mathrm{mL}^{-1}$ in ESF-921, and infected simultaneously with three baculoviruses at the following MOI: M15-2IQ (5), UNC45B / HSP90AA1 (5), ELC / RLC (5). The myosin chaperones UNC45B and HSP90AA1 we co-expressed to aid folding, in addition to essential (MYL6) and regulatory (MYL12B) muscle light chains to bind the LCBDs (Bird et al., 2014; Jiang et al., 2021). Identical expressions were performed for the shaker-2 and jordan variants. Cells were harvested at 48 - 72 hours post-infection by centrifugation at $500 \times g$ and flash frozen in liquid nitrogen.

\section{Purification of the MY015 motor domain}

$$
\text { M15-2IQ (wild-type, jordan, shaker-2) motor domains were purified from frozen Sf9 cells }
$$
following established protocols (Bird et al., 2014; Jiang et al., 2021). Cell pellets were lysed using a Dounce homogenizer in extraction buffer (concentrations in mM): MOPS (10), $\mathrm{NaCl}$ (500), EGTA (1), $\mathrm{MgCl}_{2}(10)$, ATP (2), PMSF (0.2), DTT (0.1), $\mathrm{NaN}_{3}(1)$, leupeptin $\left(2 \mu \mathrm{g} \cdot \mathrm{mL}^{-1}\right)$, protease inhibitor cocktail (Halt EDTA-free; Thermo Scientific), $\mathrm{pH}$ 7.2. Cell lysates were cleared for 30 mins at $48 \mathrm{k} \times \mathrm{g}$ and the 
719 packed into a gravity flow column and washed with a high-salt buffer, MOPS (10), $\mathrm{NaCl}$ (500), EGTA

720 (1), $\mathrm{MgCl}_{2}(5), \operatorname{ATP}(1), \operatorname{PMSF}(0.1)$, DTT (0.1), $\mathrm{NaN}_{3}(1)$, leupeptin $\left(2 \mu \mathrm{g} \cdot \mathrm{mL}^{-1}\right), \mathrm{pH} 7.2$, followed by a 721 low-salt buffer, MOPS (10), NaCl (60), EGTA (1), PMSF (0.1), DTT (0.1), $\mathrm{NaN}_{3}(1)$, leupeptin (2 $\left.722 \mu \mathrm{g} \cdot \mathrm{mL}^{-1}\right), \mathrm{pH}$ 7.0. M15-2IQ protein was eluted using low-salt buffer supplemented with $0.2 \mathrm{mg} \cdot \mathrm{mL}^{-1} 3 \mathrm{x}$ 723 FLAG peptide (American Peptide, CA). For assessment of hydrodynamic radius, purified motor 724 domains (wild-type, jordan, shaker-2) were concentrated by centrifugation (10'000 MWCO; Amicon, 725 EMD-Millipore) and directly analyzed using size exclusion chromatography (see below), alongside 726 protein size standards (Thyroglobulin (1), Ferritin (2), Aldolase (3), Conalbumin (4), Ovalbumin (5), 727 Carbonic anhydrase (6), Ribonuclease A (7); HMW + LMW gel filtration calibration kit (Cytiva). For 728 preparative scale protein production, FLAG-eluted motor domains (wild-type + jordan) were bound to a 729 strong anion exchanger (5/50 MonoQ GL; Cytiva) using a Purifier 10 chromatography system (GE 730 Healthcare). The column was washed with MOPS (10), NaCl (100), EGTA (1), PMSF (0.1), DTT (1), $\mathrm{pH} 7.0$, and a $160 \mathrm{CV}$ gradient elution performed to $1 \mathrm{M} \mathrm{NaCl}(100 \% \mathrm{~B})$. Fractions eluting at $\sim 31$ $\mathrm{mS} \cdot \mathrm{cm}^{-1}$ were concentrated $(10,000 \mathrm{MWCO})$ and further purified using size exclusion chromatography (Superdex 200, Cytiva) with isocratic elution in MOPS (10), KCl (100), EGTA (0.1), $\mathrm{NaN}_{3}$ (1), PMSF (0.1), DTT (1), leupeptin $\left(1 \mu \mathrm{g} \cdot \mathrm{mL}^{-1}\right), \mathrm{pH}$ 7.0. The M15-2IQ : ELC : RLC complex (1:1:1) eluted as a single peak and was concentrated (10,000 MWCO) before determining complex concentration at $280 \mathrm{~nm}\left(\varepsilon=88,020 \mathrm{M}^{-1} \cdot \mathrm{cm}^{-1}\right)$.

737

\section{ATPase assays}

739

Steady-state actin activated ATPase assays were measured using a NADH-coupled assay, as

740 previously reported (Bird et al., 2014). Briefly, wild-type M15-2IQ (30 nM) or jordan (150 nM) protein was assayed in the following reaction buffer (concentration in $\mathrm{mM}$ ): $\mathrm{MOPS}(10), \mathrm{KCl}(50), \mathrm{MgCl}_{2}(5)$, EGTA (0.1), MgATP (2), $40 \mathrm{U} \cdot \mathrm{mL}^{-1}$ lactate dehydrogenase (Sigma-Aldrich), $200 \mathrm{U} \cdot \mathrm{mL}^{-1}$ pyruvate kinase (Sigma-Aldrich), phosphoenolpyruvate (1) (Sigma-Aldrich), NADH (0.2), pH 7.0 at $20^{\circ} \pm 0.1^{\circ} \mathrm{C}$. Due to its lower activity, a higher concentration (150 nM) of M15-2IQ jordan protein was used. The concentration of F-actin in the reaction was titrated from 0 to $100 \mu \mathrm{M}$. The absorbance of $\mathrm{NADH}(\varepsilon=$ $6,220 \mathrm{M}^{-1} \cdot \mathrm{cm}^{-1}$ ) at $340 \mathrm{~nm}$ was measured using a dual-beam spectrophotometer (UV-1800, Shimadzu) and the ATP hydrolysis rate calculated from the change in absorbance over time. Hydrolysis rates were corrected for basal M15-2IQ ATPase activity in the absence of F-actin, and also for the ATPase activity of F-actin. ATP hydrolysis rates were fit to the Michaelis-Menten equation to estimate $k_{\text {cat }}$ and $k_{\text {ATPase }}$ using Prism (GraphPad). 
Motility chambers were assembled by coating a clean cover glass (\#1.5) with $0.1 \%$ nitrocellulose in amyl acetate (Ladd Research Industries), and attaching it to a microscope slide with two strips of double-sided adhesive tape (Scotch, $3 \mathrm{M}$ ) to form a channel approximately $3 \mathrm{~mm}$ wide. The chamber was incubated for 5 mins in $0.1 \mathrm{mg} \cdot \mathrm{mL}^{-1}$ anti-GFP (clone GFP-20, Sigma-Aldrich) diluted with motility buffer (MB) (concentrations in mM): MOPS (20), $\mathrm{KCl}(10), \mathrm{MgCl}_{2}$ (5), EGTA (0.1), $\mathrm{pH}$ 7.0. The surface was blocked using $1 \mathrm{mg} \cdot \mathrm{mL}^{-1}$ BSA (Sigma-Aldrich) diluted in MB and incubated for 1 min. After washing the chamber with MB, $1 \mu \mathrm{M}$ M15-2IQ (wild-type or jordan) diluted in MB was incubated for $1 \mathrm{~min}$ to functionalize the anti-GFP coated surface. The chamber was washed with 1 $\mathrm{mg} \cdot \mathrm{mL}^{-1} \mathrm{BSA}$ in MB, followed by MB alone. Finally, the chamber was incubated for 2 mins with TMRphalloidin stabilized actin filaments $(5 \mathrm{nM})$ diluted in $\mathrm{MB}$, and subsequently washed in $\mathrm{MB}$. Filaments were visualized using an inverted epifluorescence microscope (Olympus IX-51) and motility recorded in MB supplemented with $50 \mathrm{mM}$ DTT, $2 \mathrm{mM}$ ATP, $3 \mathrm{mM}$ glucose, $100 \mu \mathrm{g} \cdot \mathrm{mL}$ glucose oxidase, and 20 $\mu \mathrm{g} \cdot \mathrm{mL}$ catalase at $30 \pm 0.5^{\circ} \mathrm{C}$. Actin filament velocities were analyzed as described (Sellers et al., 1993).

767

\section{Polymerization assay}

769

Actin polymerization was measured using G-actin labelled on Cys 374 with N-(1-pyrene)-

770 iodoacetamide (see above), and a cuvette-based fluorometer (PTI Quantamaster 400, HORIBA Scientific) used to excite pyrene at $365 \mathrm{~nm}$ and capture fluorescence emission at $407 \mathrm{~nm}$. Gel filtered

772 G-actin (10\% pyrene labelled, with free ATP, or desalted) was converted to the physiological $\mathrm{Mg}^{2+}$ bound form by addition of $50 \mu \mathrm{M} \mathrm{MgCl}_{2}$ and $0.2 \mathrm{mM}$ EGTA for exactly two minutes at room

774 temperature. The polymerization reaction was initiated by mixing G-actin ( $3 x$ stock) with KMEI buffer (1.5x stock) in a 1:2 ratio, respectively. Myosin (wild-type or jordan) was included in the 1.5x KMEl buffer as needed. Final concentrations were $2 \mu \mathrm{M}$ G-actin and $1 \mu \mathrm{M}$ myosin, in assay buffer (concentrations in $\mathrm{mM}$ ): $\mathrm{KCl}(50), \mathrm{MgCl}_{2}$ (1), EGTA (1), imidazole (10), $\mathrm{pH} 7.0$ at $25^{\circ} \pm 0.1^{\circ} \mathrm{C}$. Data were corrected for dead-time and fluorescence recorded until the transient reached plateau, or for a maximum of 3 hours. Fluorescence derivatives with respect to time were processed in Prism (GraphPad). Half times were calculated as described (Hansen et al., 2013).

\section{TIRF single-filament polymerization assay}

783

High-tolerance cover slips (24 × $50 \mathrm{~mm}$, \#1.5, Marienfeld Superior, Germany) were cleaned by sequential sonication (10 mins each) in 2\% Hellmanex III (Hellma, Germany), $1 \mathrm{M} \mathrm{KOH}, 100 \%$ ethanol, and finally Milli-Q water. Cover slips were dried under a nitrogen stream and processed for 10 mins under argon plasma (ZEPTO, Diener Electronic, Germany). A mixture of $\mathrm{mPEG}$-silane $\left(2 \mathrm{mg} \cdot \mathrm{mL}^{-1}\right.$, 
787 Laysan Bio, AL) and biotin-PEG-silane $\left(2 \mu \mathrm{g} \cdot \mathrm{mL}^{-1}\right.$, Laysan Bio) was prepared in 96\% ethanol, $0.1 \%$ $788(\mathrm{v} / \mathrm{v}) \mathrm{HCl}$. Cover slips were coated with $100 \mu \mathrm{L}$ of the $\mathrm{mPEG}$ mixture and baked at $70^{\circ} \mathrm{C}$ for 1 hour. 789 Cover slips were rinsed twice in $96 \%$ ethanol, sonicated for 10 mins, followed by two rinses in Milli-Q, sonicated for 10 mins in Milli-Q, and finally dried under a nitrogen stream. Flow chambers were assembled using double-sided sticky tape to create a $3 \mathrm{~mm}$ wide channel on a glass slide.

792 Functionalized coverslips were placed over the tape and firmly pushed down to seal the flow chamber. 793 Immediately prior to use, flow cells were washed with buffer T50 (concentrations in $\mathrm{mM}$ ): Tris $\cdot \mathrm{HCl}$ 794 (10), $\mathrm{KCl}$ (50), DTT (1), pH 8.0. Flow cells were sequentially washed with $0.1 \mathrm{mg} \cdot \mathrm{mL}^{-1}$ (Neutravidin, 795 Thermo Scientific) in T50 for $1 \mathrm{~min}$, followed by a wash with $1 \mathrm{mg} \cdot \mathrm{mL}^{-1}$ bovine serum albumin (A0281, 796 Sigma Aldrich) in T50 for $30 \mathrm{~s}$, and a final wash of T50. Experiments were performed in the following 797 reaction buffer (final concentration in $\mathrm{mM}$ ): $\mathrm{KCl}(50), \mathrm{MgCl}_{2}$ (1), EGTA (1), imidazole (10), ATP (0.025), 798 DTT (10), glucose (15), 0.5\% methylcellulose, $20 \mu \mathrm{g} \cdot \mathrm{mL}$ catalase, $100 \mu \mathrm{g} \cdot \mathrm{mL}$ glucose oxidase, $\mathrm{pH} 7.0$. G-actin (1 $\mu \mathrm{M}$ total) was included in the reaction with TMR-actin (20\%) and biotin-actin (10\%) doping. Purified myosin motor domain $(1 \mu \mathrm{M})$ was optionally added, as needed. The reaction was loaded into the flow cell and immediately mounted onto an inverted microscope (Nikon Ti-E2) equipped with an oil immersion objective (CFI Apochromat TIRF 100x, 1.49 N.A., Nikon) for objective-style total internal reflection fluorescence (TIRF) microscopy (H-TIRF, Nikon). The flow cell was illuminated using a 561 $\mathrm{nm}$ laser line, and emission filtered using a bandpass filter (ET630/75m, Chroma). Time-lapse images were captured on an EM-CCD camera (iXon Ultra 888, Andor) controlled by NIS-Elements (AR version 5.2 , Nikon). Samples were imaged at $21 \pm 1^{\circ} \mathrm{C}$. The assay dead-time was typically $45-60 \mathrm{~s}$, and was included in data analyses.

808

Images were pre-processed in FIJI (https://fiji.sc)(Schindelin et al., 2012) by performing background subtraction and image registration (descriptor-based series registration, $2 d / 3 d+t$ ). Actin filament densities were quantified using the Analyze Particle command (size $>3$ pixel $^{2}$, circularity: 0.01.0) to count discrete particles within a $50 \times 50 \mu \mathrm{m}$ region of interest (ROI) that was randomly selected from the field of view. A minimum of 3 experiments, from two independent protein preparations, were analyzed for each condition. Filament elongation rates were calculated from time-lapse TIRF imaging sequences using kymographs generated in Elements Software (version 5.2, Nikon). At least 40 filaments from two independent experiments were analyzed for each condition.

\section{Statistical analyses}

All statistical calculations and non-linear regressions were performed in Prism (GraphPad). 
820 Regression fit parameters are quoted as mean \pm SEM, and data points as mean \pm SD, unless

821 otherwise stated. Statistical significance: ${ }^{*} p<0.05,{ }^{* *} p<0.01,{ }^{* * *} p<0.001,{ }^{* * * *} p<0.0001$.

\section{AUTHOR CONTRIBUTIONS}

824 Conceptualization:

825 Investigation:

826

827 Formal analysis:

828

829 Writing - original draft:

830 Writing - review and editing:

831 Project administration:

832 Funding acquisition:
834

835

836

837

838

839

840

841

842

843

844

845

846

\section{7}

848

849

850

851

852
JEB, MRB

ZGM, FJ, CA, MB, CFA, AS, JW, RH, DCS, SMC, AP, SM, EW, $Y T, M R B, J E B$

ZGM, FJ, CA, MB, RG, AS, CFA, JW, RH, DCS, SMC, AP, SM, EW, YT, JRS, SDMB, GMA TBF, MRB, JEB

ZGM, FJ, CA, MB, MRB, JEB

All authors.

JEB

JRS, SDMB, TBF, MRB, JEB

\section{ACKNOWLEDGEMENTS}

We thank Mireille Montcouquiol for the gift of GPSM2 antisera, James Bartles for the gift of LLC-PK1-CL4 cells, Tracy Fitzgerald at the NIDCD Mouse Auditory Testing Core for expert technical assistance, W. Clay Smith for use of fluorometry equipment, Peter Höök, H. Lee Sweeney and Tom Pollard for insightful discussions, and Peter Barr-Gillespie for critical feedback on the manuscript. This research was supported (in part) by the Intramural Research Program of the NIH (NIDCD DC000039 to TBF, NHLBI HL006049 to JRS), the Medical Research Council (MC_U142684175 to SDMB, MC_UP_1503/2 to MRB) and National Institute on Deafness and Other Communication Disorders of the National Institutes of Health under Award Number R01DC018827 (to JEB). The content is solely the responsibility of the authors and does not necessarily represent the official views of the National Institutes of Health. The funding bodies had no role in study design, data collection or analysis, decision to publish, or preparation of the manuscript.

\section{ACKNOWLEDGEMENTS}

The authors declare that no competing interests exist.

\section{REFERENCES}

Ahuja R, Pinyol R, Reichenbach N, Custer L, Klingensmith J, Kessels MM, Qualmann B (2007) Cordon-bleu is an actin nucleation factor and controls neuronal morphology. Cell 131:337-350. 
853

854

855

856

857

858

859

860

861

862

863

864

865

866

867

868

869

870

871

872

873

874

875

876

877

878

879

880

881

882

883

884

885

886

887

888

889

890

Anderson DW, Probst FJ, Belyantseva IA, Fridell RA, Beyer L, Martin DM, Wu D, Kachar B, Friedman TB, Raphael Y, Camper SA (2000) The motor and tail regions of myosin XV are critical for normal structure and function of auditory and vestibular hair cells. Hum Mol Genet 9:1729-1738.

Avenarius MR, Krey JF, Dumont RA, Morgan CP, Benson CB, Vijayakumar S, Cunningham CL, Scheffer DI, Corey DP, Müller U, Jones SM, Barr-Gillespie PG (2017) Heterodimeric capping protein is required for stereocilia length and width regulation. J Cell Biol 216:3861-3881.

Avraham KB, Hasson T, Steel KP, Kingsley DM, Russell LB, Mooseker MS, Copeland NG, Jenkins NA (1995) The mouse Snell's waltzer deafness gene encodes an unconventional myosin required for structural integrity of inner ear hair cells. Nat Genet 11:369-375.

Bariani P, De Chiffre L, Hansen HN, Horsewell A (2005) Investigation on the traceability of three dimensional scanning electron microscope measurements based on the stereo-pair technique. Precis Eng 29:219-228.

Barr-Gillespie P-G (2015) Assembly of hair bundles, an amazing problem for cell biology. Mol Biol Cell 26:2727-2732.

Belyantseva IA, Boger ET, Friedman TB (2003) Myosin XVa localizes to the tips of inner ear sensory cell stereocilia and is essential for staircase formation of the hair bundle. Proc Natl Acad Sci U S A 100:13958-13963.

Belyantseva IA, Boger ET, Naz S, Frolenkov GI, Sellers JR, Ahmed ZM, Griffith AJ, Friedman TB (2005) Myosin-XVa is required for tip localization of whirlin and differential elongation of hair-cell stereocilia. Nat Cell Biol 7:148-156.

Beurg M, Fettiplace R, Nam J-H, Ricci AJ (2009) Localization of inner hair cell mechanotransducer channels using high-speed calcium imaging. Nat Neurosci 12:553-558.

Bird JE, Barzik M, Drummond MC, Sutton DC, Goodman SM, Morozko EL, Cole SM, Boukhvalova AK, Skidmore J, Syam D, Wilson EA, Fitzgerald T, Rehman AU, Martin DM, Boger ET, Belyantseva IA, Friedman TB (2017) Harnessing molecular motors for nanoscale pulldown in live cells. Mol Biol Cell 28:463-475.

Bird JE, Takagi Y, Billington N, Strub M-P, Sellers JR, Friedman TB (2014) Chaperone-enhanced purification of unconventional myosin 15, a molecular motor specialized for stereocilia protein trafficking. Proc Natl Acad Sci U S A 111:12390-12395.

Brawley CM, Rock RS (2009) Unconventional myosin traffic in cells reveals a selective actin cytoskeleton. Proc Natl Acad Sci U S A 106:9685-9690.

Cooper JA, Walker SB, Pollard TD (1983) Pyrene actin: documentation of the validity of a sensitive assay for actin polymerization. J Muscle Res Cell Motil 4:253-262.

Criddle AH, Geeves MA, Jeffries T (1985) The use of actin labelled with N-(1-pyrenyl)iodoacetamide to study the interaction of actin with myosin subfragments and troponin/tropomyosin. Biochem $\mathrm{J}$ 232:343-349.

Delprat B, Michel V, Goodyear R, Yamasaki Y, Michalski N, El-Amraoui A, Perfettini I, Legrain P, Richardson G, Hardelin J-P, Petit C (2005) Myosin XVa and whirlin, two deafness gene products 
bioRxiv preprint doi: https://doi.org/10.1101/2021.07.09.451618; this version posted July 13, 2021. The copyright holder for this preprint (which was not certified by peer review) is the author/funder, who has granted bioRxiv a license to display the preprint in perpetuity. It is made available under aCC-BY-NC-ND 4.0 International license.

891 required for hair bundle growth, are located at the stereocilia tips and interact directly. Hum Mol Genet 14:401-410.

893 Dominguez R, Holmes KC (2011) Actin structure and function. Annu Rev Biophys 40:169-186.

894 Drummond MC, Barzik M, Bird JE, Zhang D-S, Lechene CP, Corey DP, Cunningham LL, Friedman TB (2015) Live-cell imaging of actin dynamics reveals mechanisms of stereocilia length regulation in the inner ear. Nat Commun 6:6873.

897 Dunbar LA et al. (2019) Clarin-2 is essential for hearing by maintaining stereocilia integrity and 898 function. EMBO Mol Med 11:e10288.

899 Ebrahim S, Avenarius MR, Grati M, Krey JF, Windsor AM, Sousa AD, Ballesteros A, Cui R, Millis BA, 900 901 902 PG, Kachar B (2016) Stereocilia-staircase spacing is influenced by myosin III motors and their cargos espin-1 and espin-like. Nat Commun 7:10833.

907

908

909

Ezan J, Lasvaux L, Gezer A, Novakovic A, May-Simera H, Belotti E, Lhoumeau A-C, Birnbaumer L, Beer-Hammer S, Borg J-P, Le Bivic A, Nürnberg B, Sans N, Montcouquiol M (2013) Primary cilium migration depends on G-protein signalling control of subapical cytoskeleton. Nat Cell Biol 15:11071115.

Fang Q, Indzhykulian AA, Mustapha M, Riordan GP, Dolan DF, Friedman TB, Belyantseva IA, Frolenkov GI, Camper SA, Bird JE (2015) The 133-kDa N-terminal domain enables myosin 15 to maintain mechanotransducing stereocilia and is essential for hearing. eLife 4.

Fievez S, Carlier MF (1993) Conformational changes in subdomain-2 of G-actin upon polymerization into F-actin and upon binding myosin subfragment-1. FEBS Lett 316:186-190.

912 Fievez S, Carlier MF, Pantaloni D (1997a) Mechanism of myosin subfragment-1-induced assembly of 913 CaG-actin and MgG-actin into F-actin-S1-decorated filaments. Biochemistry 36:11843-11850.

914 Fievez S, Pantaloni D, Carlier MF (1997b) Kinetics of myosin subfragment-1-induced condensation of 915 916 G-actin into oligomers, precursors in the assembly of F-actin-S1. Role of the tightly bound metal ion and ATP hydrolysis. Biochemistry 36:11837-11842.

Flock A, Cheung HC (1977) Actin filaments in sensory hairs of inner ear receptor cells. J Cell Biol 75:339-343.

922 Fujiwara I, Takahashi S, Tadakuma H, Funatsu T, Ishiwata S (2002) Microscopic analysis of 923 polymerization dynamics with individual actin filaments. Nat Cell Biol 4:666-673. gene for congenital, recessive deafness DFNB3 maps to the pericentromeric region of chromosome 17. Nat Genet 9:86-91. 
927

928

929

930

931

932

933

934

935

936

937

938

939

940

941

942

943

944

945

946

947

948

949

950

951

952

953

954

955

956

957

958

959

960

961

962

Gong R, Jiang F, Moreland ZG, Reynolds M, Espinosa de los Reyes S, Gurel PS, Shams A, Bowl MR, Bird JE, Alushin GM (2021) Structural basis for tunable control of actin dynamics by myosin-15 in mechanosensory stereocilia. bioRxiv 2021.07.09.451843.

Hansen SD, Zuchero JB, Mullins RD (2013) Cytoplasmic actin: purification and single molecule assembly assays. Methods Mol Biol Clifton NJ 1046:145-170.

Hardisty-Hughes RE, Parker A, Brown SDM (2010) A hearing and vestibular phenotyping pipeline to identify mouse mutants with hearing impairment. Nat Protoc 5:177-190.

Hartman MA, Spudich JA (2012) The myosin superfamily at a glance. J Cell Sci 125:1627-1632.

Hasson T, Gillespie PG, Garcia JA, MacDonald RB, Zhao Y, Yee AG, Mooseker MS, Corey DP (1997) Unconventional myosins in inner-ear sensory epithelia. J Cell Biol 137:1287-1307.

Heissler SM, Sellers JR (2016) Various Themes of Myosin Regulation. J Mol Biol 428:1927-1946.

Holt JR, Gillespie SKH, Provance DW, Shah K, Shokat KM, Corey DP, Mercer JA, Gillespie PG (2002) A chemical-genetic strategy implicates myosin-1c in adaptation by hair cells. Cell 108:371-381.

Hopkins R, Esposito D (2009) A rapid method for titrating baculovirus stocks using the Sf-9 Easy Titer cell line. BioTechniques 47:785-788.

Houdusse A, Sweeney HL (2016) How Myosin Generates Force on Actin Filaments. Trends Biochem Sci 41:989-997.

Jiang F, Takagi Y, Shams A, Heissler SM, Friedman TB, Sellers JR, Bird JE (2021) The ATPase mechanism of myosin 15, the molecular motor mutated in DFNB3 human deafness. J Biol Chem 296:100243.

Kaltenbach JA, Falzarano PR, Simpson TH (1994) Postnatal development of the hamster cochlea. II. Growth and differentiation of stereocilia bundles. J Comp Neurol 350:187-198.

Kerber ML, Jacobs DT, Campagnola L, Dunn BD, Yin T, Sousa AD, Quintero OA, Cheney RE (2009) A novel form of motility in filopodia revealed by imaging myosin- $X$ at the single-molecule level. Curr Biol CB 19:967-973.

Kinosian HJ, Selden LA, Estes JE, Gershman LC (1993) Actin filament annealing in the presence of ATP and phalloidin. Biochemistry 32:12353-12357.

Krey JF, Barr-Gillespie PG (2019) Molecular Composition of Vestibular Hair Bundles. Cold Spring Harb Perspect Med 9:a033209.

Krey JF, Chatterjee P, Dumont RA, O'Sullivan M, Choi D, Bird JE, Barr-Gillespie PG (2020) Mechanotransduction-Dependent Control of Stereocilia Dimensions and Row Identity in Inner Hair Cells. Curr Biol CB 30:442-454.e7.

Kuhn JR, Pollard TD (2005) Real-time measurements of actin filament polymerization by total internal reflection fluorescence microscopy. Biophys J 88:1387-1402.

Lheureux K, Forné T, Chaussepied P (1993) Interaction and polymerization of the G-actin-myosin head complex: effect of DNase I. Biochemistry 32:10005-10014. 
963

964

965

966

967

968

969

970

971

972

973

974

975

976

977

978

979

980

981

982

983

984

985

986

987

988

989

990

991

992

993

994

995

996

997

998

999

Li X-D, Ikebe R, Ikebe M (2005) Activation of myosin Va function by melanophilin, a specific docking partner of myosin Va. J Biol Chem 280:17815-17822.

Liang Y, Wang A, Belyantseva IA, Anderson DW, Probst FJ, Barber TD, Miller W, Touchman JW, Jin L, Sullivan SL, Sellers JR, Camper SA, Lloyd RV, Kachar B, Friedman TB, Fridell RA (1999) Characterization of the human and mouse unconventional myosin XV genes responsible for hereditary deafness DFNB3 and shaker 2. Genomics 61:243-258.

Liu J, Taylor DW, Krementsova EB, Trybus KM, Taylor KA (2006) Three-dimensional structure of the myosin V inhibited state by cryoelectron tomography. Nature 442:208-211.

Machesky LM, Atkinson SJ, Ampe C, Vandekerckhove J, Pollard TD (1994) Purification of a cortical complex containing two unconventional actins from Acanthamoeba by affinity chromatography on profilin-agarose. J Cell Biol 127:107-115.

Manor U, Disanza A, Grati M, Andrade L, Lin H, Di Fiore PP, Scita G, Kachar B (2011) Regulation of stereocilia length by myosin XVa and whirlin depends on the actin-regulatory protein Eps8. Curr Biol CB 21:167-172.

Mauriac SA, Hien YE, Bird JE, Carvalho SD-S, Peyroutou R, Lee SC, Moreau MM, Blanc J-M, Geyser A, Medina C, Thoumine O, Beer-Hammer S, Friedman TB, Rüttiger L, Forge A, Nürnberg B, Sans N, Montcouquiol M (2017) Defective Gpsm2/Gai3 signalling disrupts stereocilia development and growth cone actin dynamics in Chudley-McCullough syndrome. Nat Commun 8:14907.

Mburu P et al. (2003) Defects in whirlin, a PDZ domain molecule involved in stereocilia elongation, cause deafness in the whirler mouse and families with DFNB31. Nat Genet 34:421-428.

Mianné J, Chessum L, Kumar S, Aguilar C, Codner G, Hutchison M, Parker A, Mallon A-M, Wells S, Simon MM, Teboul L, Brown SDM, Bowl MR (2016) Correction of the auditory phenotype in C57BL/6N mice via CRISPR/Cas9-mediated homology directed repair. Genome Med 8:16.

Miller L, Phillips M, Reisler E (1988) Polymerization of G-actin by myosin subfragment 1. J Biol Chem 263:1996-2002.

Mullins RD, Heuser JA, Pollard TD (1998) The interaction of Arp2/3 complex with actin: nucleation, high affinity pointed end capping, and formation of branching networks of filaments. Proc Natl Acad Sci U S A 95:6181-6186.

Mullins RD, Stafford WF, Pollard TD (1997) Structure, subunit topology, and actin-binding activity of the Arp2/3 complex from Acanthamoeba. J Cell Biol 136:331-343.

Murphy DB, Gray RO, Grasser WA, Pollard TD (1988) Direct demonstration of actin filament annealing in vitro. J Cell Biol 106:1947-1954.

Nagy S, Ricca BL, Norstrom MF, Courson DS, Brawley CM, Smithback PA, Rock RS (2008) A myosin motor that selects bundled actin for motility. Proc Natl Acad Sci U S A 105:9616-9620.

Narayanan P, Chatterton P, Ikeda A, Ikeda S, Corey DP, Ervasti JM, Perrin BJ (2015) Length regulation of mechanosensitive stereocilia depends on very slow actin dynamics and filament-severing proteins. Nat Commun 6:6855. 
bioRxiv preprint doi: https://doi.org/10.1101/2021.07.09.451618; this version posted July 13, 2021. The copyright holder for this preprint (which was not certified by peer review) is the author/funder, who has granted bioRxiv a license to display the preprint in perpetuity. It is made available under aCC-BY-NC-ND 4.0 International license.

000

001

002

003

004

005

006

007

008

009

010

011

012

013

014

015

016

017

018

019

020

021

022

023

024

025

026

027

028

029

030

031

032

033

034

035

Okreglak V, Drubin DG (2010) Loss of Aip1 reveals a role in maintaining the actin monomer pool and an in vivo oligomer assembly pathway. J Cell Biol 188:769-777.

Pato MD, Sellers JR, Preston YA, Harvey EV, Adelstein RS (1996) Baculovirus expression of chicken nonmuscle heavy meromyosin II-B. Characterization of alternatively spliced isoforms. J Biol Chem 271:2689-2695.

Peng AW, Belyantseva IA, Hsu PD, Friedman TB, Heller S (2009) Twinfilin 2 regulates actin filament lengths in cochlear stereocilia. J Neurosci Off J Soc Neurosci 29:15083-15088.

Potter PK et al. (2016) Novel gene function revealed by mouse mutagenesis screens for models of age-related disease. Nat Commun 7:12444.

Probst FJ, Fridell RA, Raphael Y, Saunders TL, Wang A, Liang Y, Morell RJ, Touchman JW, Lyons $\mathrm{RH}$, Noben-Trauth K, Friedman TB, Camper SA (1998) Correction of deafness in shaker-2 mice by an unconventional myosin in a BAC transgene. Science 280:1444-1447.

Quinlan ME, Heuser JE, Kerkhoff E, Mullins RD (2005) Drosophila Spire is an actin nucleation factor. Nature 433:382-388.

Rehman AU, Bird JE, Faridi R, Shahzad M, Shah S, Lee K, Khan SN, Imtiaz A, Ahmed ZM, Riazuddin S, Santos-Cortez RLP, Ahmad W, Leal SM, Riazuddin S, Friedman TB (2016) Mutational Spectrum of MYO15A and the Molecular Mechanisms of DFNB3 Human Deafness. Hum Mutat 37:991-1003.

Reymann A-C, Boujemaa-Paterski R, Martiel J-L, Guérin C, Cao W, Chin HF, De La Cruz EM, Théry M, Blanchoin L (2012) Actin network architecture can determine myosin motor activity. Science 336:1310-1314.

Richardson GP, de Monvel JB, Petit C (2011) How the genetics of deafness illuminates auditory physiology. Annu Rev Physiol 73:311-334.

Ropars V, Yang Z, Isabet T, Blanc F, Zhou K, Lin T, Liu X, Hissier P, Samazan F, Amigues B, Yang ED, Park H, Pylypenko O, Cecchini M, Sindelar CV, Sweeney HL, Houdusse A (2016) The myosin X motor is optimized for movement on actin bundles. Nat Commun 7:12456.

Rzadzinska AK, Schneider ME, Davies C, Riordan GP, Kachar B (2004) An actin molecular treadmill and myosins maintain stereocilia functional architecture and self-renewal. J Cell Biol 164:887-897.

Sagot I, Rodal AA, Moseley J, Goode BL, Pellman D (2002) An actin nucleation mechanism mediated by Bni1 and profilin. Nat Cell Biol 4:626-631.

Sakai T, Umeki N, Ikebe R, Ikebe M (2011) Cargo binding activates myosin VIIA motor function in cells. Proc Natl Acad Sci U S A 108:7028-7033.

Salles FT, Merritt RC, Manor U, Dougherty GW, Sousa AD, Moore JE, Yengo CM, Dosé AC, Kachar B (2009) Myosin Illa boosts elongation of stereocilia by transporting espin 1 to the plus ends of actin filaments. Nat Cell Biol 11:443-450.

Sato O, Li X-D, Ikebe M (2007) Myosin Va becomes a low duty ratio motor in the inhibited form. J Biol Chem 282:13228-13239. 
bioRxiv preprint doi: https://doi.org/10.1101/2021.07.09.451618; this version posted July 13, 2021. The copyright holder for this preprint (which was not certified by peer review) is the author/funder, who has granted bioRxiv a license to display the preprint in perpetuity. It is made available under aCC-BY-NC-ND 4.0 International license.

036

037

038

039

040

041

042

043

044

045

046

047

048

049

050

051

052

053

054

055

056

057

058

059

060

061

062

063

064

065

066

067

068

069

070

Schindelin J, Arganda-Carreras I, Frise E, Kaynig V, Longair M, Pietzsch T, Preibisch S, Rueden C, Saalfeld S, Schmid B, Tinevez J-Y, White DJ, Hartenstein V, Eliceiri K, Tomancak P, Cardona A (2012) Fiji: an open-source platform for biological-image analysis. Nat Methods 9:676-682.

Schneider ME, Belyantseva IA, Azevedo RB, Kachar B (2002) Rapid renewal of auditory hair bundles. Nature 418:837-838.

Sckolnick M, Krementsova EB, Warshaw DM, Trybus KM (2013) More than just a cargo adapter, melanophilin prolongs and slows processive runs of myosin Va. J Biol Chem 288:29313-29322.

Sellers JR, Cuda G, Wang F, Homsher E (1993) Myosin-specific adaptations of the motility assay. Methods Cell Biol 39:23-49.

Sept D, Xu J, Pollard TD, McCammon JA (1999) Annealing accounts for the length of actin filaments formed by spontaneous polymerization. Biophys J 77:2911-2919.

Shin J-B, Streijger F, Beynon A, Peters T, Gadzalla L, McMillen D, Bystrom C, Van der Zee CEEM, Wallimann T, Gillespie PG (2007) Hair Bundles Are Specialized for ATP Delivery via Creatine Kinase. Neuron 53:371-386.

Spudich JA, Watt S (1971) The regulation of rabbit skeletal muscle contraction. I. Biochemical studies of the interaction of the tropomyosin-troponin complex with actin and the proteolytic fragments of myosin. J Biol Chem 246:4866-4871.

Stepanyan R, Belyantseva IA, Griffith AJ, Friedman TB, Frolenkov GI (2006) Auditory mechanotransduction in the absence of functional myosin-XVa. J Physiol 576:801-808.

Tadenev ALD, Akturk A, Devanney N, Mathur PD, Clark AM, Yang J, Tarchini B (2019) GPSM2-GNAI Specifies the Tallest Stereocilia and Defines Hair Bundle Row Identity. Curr Biol CB 29:921-934.e4.

Tarchini B, Tadenev ALD, Devanney N, Cayouette M (2016) A link between planar polarity and staircase-like bundle architecture in hair cells. Dev Camb Engl 143:3926-3932.

Thirumurugan K, Sakamoto T, Hammer JA, Sellers JR, Knight PJ (2006) The cargo-binding domain regulates structure and activity of myosin 5 . Nature 442:212-215.

Tilney LG, Cotanche DA, Tilney MS (1992) Actin filaments, stereocilia and hair cells of the bird cochlea. VI. How the number and arrangement of stereocilia are determined. Dev Camb Engl 116:213-226.

Tilney LG, Derosier DJ, Mulroy MJ (1980) The organization of actin filaments in the stereocilia of cochlear hair cells. J Cell Biol 86:244-259.

Umeki N, Jung HS, Sakai T, Sato O, Ikebe R, Ikebe M (2011) Phospholipid-dependent regulation of the motor activity of myosin X. Nat Struct Mol Biol 18:783-788.

Umeki N, Jung HS, Watanabe S, Sakai T, Li X, Ikebe R, Craig R, Ikebe M (2009) The tail binds to the head-neck domain, inhibiting ATPase activity of myosin VIIA. Proc Natl Acad Sci U S A 106:84838488. 
071 Vélez-Ortega AC, Freeman MJ, Indzhykulian AA, Grossheim JM, Frolenkov GI (2017)

072 Mechanotransduction current is essential for stability of the transducing stereocilia in mammalian

073 auditory hair cells. eLife 6.

074 Vélez-Ortega AC, Frolenkov GI (2019) Building and repairing the stereocilia cytoskeleton in

075 mammalian auditory hair cells. Hear Res 376:47-57.

076 Wang A, Liang Y, Fridell RA, Probst FJ, Wilcox ER, Touchman JW, Morton CC, Morell RJ, Noben-

077 Trauth K, Camper SA, Friedman TB (1998) Association of unconventional myosin MYO15 mutations

078 with human nonsyndromic deafness DFNB3. Science 280:1447-1451.

079 Xiong W, Wagner T, Yan L, Grillet N, Müller U (2014) Using injectoporation to deliver genes to 080 mechanosensory hair cells. Nat Protoc 9:2438-2449.

081 Yagi K, Mase R, Sakakibara I, Asai H (1965) FUNCTION OF HEAVY MEROMYOSIN IN THE 082 ACCELERATION OF ACTIN POLYMERIZATION. J Biol Chem 240:2448-2454.

083 Yang Y, Baboolal TG, Siththanandan V, Chen M, Walker ML, Knight PJ, Peckham M, Sellers JR 084 (2009) A FERM domain autoregulates Drosophila myosin 7a activity. Proc Natl Acad Sci U S A 085 106:4189-4194.

086 Young G et al. (2018) Quantitative mass imaging of single biological macromolecules. Science $087 \quad 360: 423-427$.

088 Zampini V, Rüttiger L, Johnson SL, Franz C, Furness DN, Waldhaus J, Xiong H, Hackney CM, Holley 089 MC, Offenhauser N, Di Fiore PP, Knipper M, Masetto S, Marcotti W (2011) Eps8 regulates hair bundle 090 length and functional maturation of mammalian auditory hair cells. PLoS Biol 9:e1001048.

091 Zhang D-S, Piazza V, Perrin BJ, Rzadzinska AK, Poczatek JC, Wang M, Prosser HM, Ervasti JM, 092 Corey DP, Lechene CP (2012) Multi-isotope imaging mass spectrometry reveals slow protein turnover 093 in hair-cell stereocilia. Nature 481:520-524.

094 Zheng L, Zheng J, Whitlon DS, García-Añoveros J, Bartles JR (2010) Targeting of the hair cell 095 proteins cadherin 23, harmonin, myosin XVa, espin, and prestin in an epithelial cell model. J Neurosci 096 Off J Soc Neurosci 30:7187-7201. 


\section{FIGURE 1}

103

104

105

106

107

108

109

110

111

112

113

114

115

116

117

118

119

120

121

122

123

124

125

126

127

128

129

130

131

132 133

A) Schematic showing the protein domains of the long (MYO15-1) and short (MYO15-2) isoforms encoded by the Myo15 gene. The jordan and shaker-2 deafness mutations are shown. B) ABR phenotyping of the jordan pedigree at 3 months identified 10 mice with statistically elevated hearing thresholds (red circles) for click and at 8,16 and $32 \mathrm{kHz}$ stimuli, compared to their normal hearing pedigree mates ( $n=73$, black circles). Statistical outliers were detected using robust regression and outlier removal (red circles, ROUT, $Q=1 \%$ ). Thresholds of affected mice that did not respond to the highest intensity stimulus ( $90 \mathrm{~dB}$ SPL) are recorded as $95 \mathrm{~dB}$ SPL. Data are mean $\pm \mathrm{SD}$. C)

Evolutionary conservation of the aspartate (D) residue of MYO15 altered to glycine (G) in jordan mice that causes hearing loss. Residue positions refer to mouse MY015-1 (NP_034992.2). D) ABR recordings of $M y 015^{j / / s h 2}$ compound heterozygotes at P28 shows profound hearing loss, with

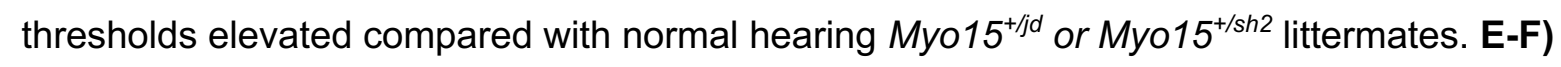
Longitudinal auditory phenotyping of jordan mice at 1- $(E)$ and 3- $(F)$ months of age. ABR recordings show that $M y 015^{j d j d i}$ mice (red, $n=10$ ) exhibit a progressive, moderate-to-severe hearing loss affecting all frequencies, whereas age-matched $M y 015^{+/+}($black, $n=10)$ and $M y 015^{+j d}($ grey, $n=15)$ littermate

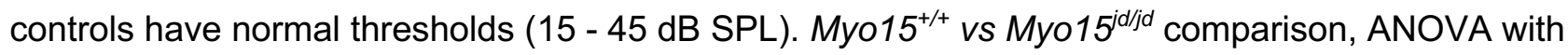
Tukey's multiple comparisons test.

\section{FIGURE 2}

A-F) Representative SEM images of stereocilia bundles from $M y 015^{+/+}, M y 015^{j d / j d}$, and $M y 015^{\text {sh } 2 / s h 2}$

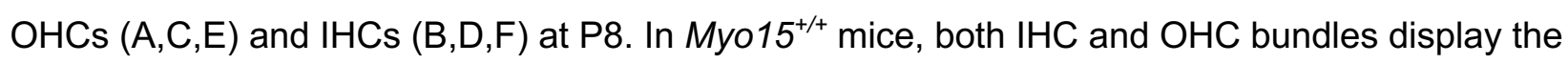
characteristic staircase architecture with 3 stereocilia ranks of increasing height. $\mathrm{IHC}$ and $\mathrm{OHC}$ bundles from either Myo1 $5^{j / d j d}$ and $M y 015^{s h / s h 2}$ mice are shorter in height than the wild-type bundles. Myo15 $5^{\text {jdjd }}$ stereocilia taper in height towards the periphery of the bundle (white arrows). G) Projected heights of tallest (row 1) OHC stereocilia at P8 are $1.2 \pm 0.1 \mu \mathrm{m}\left(\mathrm{Myo1}^{+/+}, 58\right.$ stereocilia from 4 mice), $0.8 \pm 0.1 \mu \mathrm{m}\left(\right.$ Myo1 $5^{\mathrm{j} / \mathrm{j} d \mathrm{~d}}, 60$ stereocilia from $\left.4 \mathrm{mice}\right)$, and $0.4 \pm 0.1 \mu \mathrm{m}\left(\mathrm{Myo1} 5^{\mathrm{sh} / \mathrm{sh} 2}, 50 \mathrm{stereocilia}\right.$ from 2 mice). $\mathrm{H}$ ) Projected heights of tallest (row 1) $\mathrm{IHC}$ stereocilia at P8 are $2.2 \pm 0.2 \mu \mathrm{m}\left(\mathrm{Myo1}^{+/+}, 47\right.$ stereocilia from 4 mice), $1.3 \pm 0.1 \mu \mathrm{m}$ (Myo1 $5^{j d j / d}, 47$ stereocilia from 4 mice), and $0.9 \pm 0.1 \mu \mathrm{m}$ $\left(M y 015^{\text {sh2/sh2 }}, 30\right.$ stereocilia from 2 mice). Brown-Forsythe and Welch ANOVA with Dunnett's T3 multiple comparisons test. Images are from mid-cochlear turn. Scale bars, $1 \mu \mathrm{m}$. 
FIGURE 3

A,B) Immunofluorescence (IF) confocal images showing anti-MYO15 (green, PB48) in control Myo15 ${ }^{+/ j d}$, Myo15 ${ }^{\text {sh2/sh2 }}$ and Myo15 jd/jd $\mathrm{IHCs}$ fixed at P14 (A), or P7 (B). Phalloidin was used to label F-actin (magenta). C) IF confocal images of elongation complex proteins (green) in control Myo15 $5^{+/ j d}$ and Myo15 joljd $\mathrm{IHCs}$ fixed at P7, overlaid with phalloidin labelled F-actin (magenta). Images are representative of data from at least two independent animals per genotype / antibody, and are shown as maximum intensity projections reconstructed from z-stacks. Scale bars, $10 \mu \mathrm{m}$.

\section{FIGURE 4}

143 A) Actin barbed-end assay in detergent-permeabilized hair cells from mouse cochlear explant cultures at P6. TMR-labelled G-actin (green) was added prior to fixation to identify uncapped barbed ends. Phalloidin labelling of F-actin (magenta) is overlaid. In both Myo15 jd/jd and littermate Myo15 ${ }^{+/ j d}$ controls, barbed-ends were detected at row 2 stereocilia tips, and at the tips of all stereocilia rows in Myo15 $5^{\text {sh2/sh2 }}$ hair cells. B) HeLa cells were transfected with EGFP-tagged Myo15-2 expression constructs or EGFP (wt) trafficked to filopodia tips (red arrowheads), while EGFP-M15 (jd) and EGFP-M15 (sh2) did not. Myo15-2 and prepared as above. Both EGFP-M15 (wt) and EGFP-M15 (jd) concentrated at microvillar tips, while EGFP-M15 (sh2) did not. Orthogonal projections are shown (inverted grayscale). Images are representative from at least three independent experiments. Scale bars, $2 \mu \mathrm{m}(A) ; 20 \mu \mathrm{m}(B+C)$.

FIGURE 5

A) Cartoon of MYO15 motor domains expressed in Sf9 cells, consisting of the ATPase and two light chain binding domains (LCBD). B) Size exclusion chromatography analysis of FLAG/IEX purified M15(wt) and M15(jd) proteins. M15(sh2) elutes close to the void volume (arrow) and was aggregated. Protein calibration standards (dotted lines), FLAG peptide (asterisk). C) SDS-PAGE analysis of SEC purified motor domain proteins. The motor domain (arrow) co-purifies with RLC and ELC light chains for all variants. M15(sh2) was misfolded and extracted from Sf9 cells at low yield. D) Steady-state ATPase activation of M15(wt) and M15(jd) motor domains measured using a NADH-coupled assay at $20 \pm 0.1^{\circ} \mathrm{C}$. Reactions were performed with [F-actin] as shown. Rectangular hyperbola fits are shown for M15(wt) (blue, $\left.k_{\text {cat }}=5.8 \pm 0.2 \mathrm{~s}^{-1}, k_{\text {ATPase }}=29.1 \pm 2.1 \mu \mathrm{M}\right)$ and for M15(jd) (green, $k_{\text {cat }}=0.87 \pm 0.04$ $\left.\mathrm{s}^{-1}, k_{\text {ATPase }}=114.3 \pm 8.2 \mu \mathrm{M}, \mathrm{n}=4\right)$. E) Frequency histogram of F-actin velocities in a gliding filament 
168

169

170

171

172

173

174

175

176

177

178

179

180

181

182

183

184

185

186

187

188

189

190

191

192

193

194

195

196

197

198

199

200

201

filaments, mean \pm SD $)$ and M15(jd) $\left(216 \pm 71 \mathrm{~nm} \cdot \mathrm{s}^{-1}, \mathrm{n}=2844\right.$ filaments $)$. Data are from 2 independent experiments.

\section{FIGURE 6}

A) Fluorescent time-course of $2 \mu \mathrm{M}$ G-actin (10\% pyrene) measured in a fluorimeter (red trace). Polymerization was induced by addition of KMEI (1x) at $t=0 \mathrm{~s}$. Introduction of $1 \mu \mathrm{M} \mathrm{M15(wt)} \mathrm{(blue)} \mathrm{at} t$ $=0 \mathrm{~s}$ increases in actin polymerization following an inflexion point (arrow), whilst $1 \mu \mathrm{M} M 15(\mathrm{jd})$ (green) does not (arrow). Reactions contains $70 \mu \mathrm{M}$ ATP carried over from the actin storage G-buffer. B) First derivative of pyrene fluorescence with respect to time for G-actin + M15(wt)(blue) and G-actin + M15(jd)(green). C) Fluorescent time course of $2 \mu \mathrm{M}$ G-actin (10\% pyrene) induced to polymerize by KMEI buffer in the absence of free ATP (red trace). G-actin monomers were desalted immediately prior to use, ensuring they were ATP bound. Addition of $1 \mu \mathrm{M} \mathrm{M15(wt)} \mathrm{(blue)} \mathrm{triggers} \mathrm{an} \mathrm{almost}$ immediate increase in actin polymerization. D) Quantification of time to reach half maximal fluorescence $(n=4)$.

\section{FIGURE 7}

A) TIRFM visualization of actin filaments polymerizing on PEG-biotin-neutravidin functionalized cover glass. Polymerization of $1 \mu \mathrm{M}$ G-actin ( $20 \%$ TMR $+10 \%$ biotin labelled) was induced by $1 \times$ KMEI (50 $\mathrm{mM} \mathrm{KCl}, 1 \mathrm{mM} \mathrm{MgCl} 2,1 \mathrm{mM} \mathrm{EGTA}, 10 \mathrm{mM}$ imidazole, $\mathrm{pH} \mathrm{7.0)}$ ) at $\mathrm{t}=0 \mathrm{~s}$, in the presence of $25 \mu \mathrm{M}$ ATP. Representative time-lapses shown for: $1 \mu \mathrm{M} \mathrm{G}$-actin (top), $1 \mu \mathrm{M}$ G-actin $+1 \mu \mathrm{M} \mathrm{M15(wt)} \mathrm{(middle),} \mathrm{and}$ $1 \mu \mathrm{M}$ G-actin $+1 \mu \mathrm{M}$ mutant M15(jd) (bottom). B) Quantification of actin filament density shows delayed nucleation activity of MYO15 in the presence of ATP. C) Kymographs of actin filament elongation. D) Barbed end elongation rates for G-actin alone (red), G-actin + M15(wt) (blue), G-actin + M15(jd) (green). $E+F$ ) Elongation rate data (from $D$ ) re-binned as before $(E)$, or after $(F)$ nucleation. The G-actin + KMEI control data set (from D) is reproduced identically as a comparator in $E$ and F. G) Time-lapse of actin filaments polymerization induced by KMEl at $t=0 \mathrm{~s}$, with no ATP in solution. G-actin (ATP) monomers were prepared by desalting into ATP-free G-buffer. H) Actin filament density shows nucleation activity of MY015 is accelerated in the absence of ATP. I) Barbed end filament rates in the absence of free ATP. Reaction deadtimes were typically $50 \mathrm{~s}$ and included in quantification. TIRFM images are shown as inverted grayscale. Scale bars are $10 \mu \mathrm{m}(\mathrm{A}, \mathrm{G})$. Data are from 4 experiments, using 2 independent protein preparations. 


\section{FIGURE S1}

A) Whole genome SNP mapping of genomic DNA from ten MPC190 mice exhibiting hearing loss (red, $\mathrm{HL}$ ) and three hearing $(\mathrm{H})$ littermate controls. The genotype of each mouse is either homozygous for C57BL/6J (black box), C3H (white box) or heterozygous (grey box) for each marker. The analysis defined a 16.5Mb critical interval on Chromosome 11 between markers rs29410974 and rs26906764 (Chr11:50420012-67162951, GRCm38). B) Sanger sequencing confirmed the only WGS-identified, coding lesion (arrow) within the critical interval, in exon 17 (ENSMUSE00000244718) of the Myo15 gene (ENSMUSG00000042678). A nucleotide transition (c.4940A>G) at codon 1647 alters the wildtype aspartate (D) codon to a mutant glycine (G). Example electropherograms are shown for $M y o 15^{+/+}$,

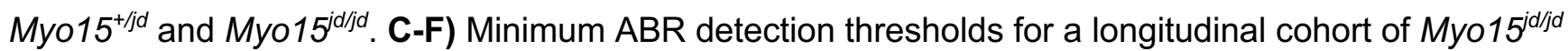
mice $(n=10)$, Myo15 $^{+/+}(n=10)$ and Myo15 ${ }^{+/ j d}(n=15)$ littermates at 4, 6, 9 and 12 weeks reveal progressive hearing loss. Data points represent individual mice, with the mean value indicated. ${ }^{* * *} p$ $<0.0001$; two-way ANOVA with Tukey's multiple comparisons test. G) Distortion Product Otoacoustic Emission (DPOAE) responses are greatly reduced at 12 weeks in Myo15 jd/jd mutants $(\mathrm{red}, \mathrm{n}=10)$ at all frequencies tested compared with Myo15 $^{+/+}$(black, $n=9$ ) and Myo15 ${ }^{+/ j d}$ (gray, $n=14$ ) littermates.

Data are mean \pm SD.

\section{FIGURE S2}

A) SEM analyses of IHC bundles from Myo15 jd/jd and $M y o 15^{+/+}$littermates at 12 weeks. B)

Quantification of the tallest (row 1) stereocilia at 12 weeks in IHCs from Myo15 ${ }^{+/+}$mice (45 stereocilia from 3 animals) and Myo15 jd/jd mice (45 stereocilia from 3 animals). ${ }^{* * *} p<0.0001$, unpaired, twotailed $t$-test. C) SEM analyses of $M y 015^{\text {jd/jd }} \mathrm{OHC}$ bundles at 12 weeks. OHC bundles were qualitatively categorized as "intact", "abnormal/damaged" or "missing". Representative examples are shown. In the "abnormal/damaged" group, stereocilia were typically resorbed from the periphery of the hair bundle. D) Quantification of $\mathrm{OHC}$ bundle categories at 12 weeks in $M y 015^{+/+}(1344 \mathrm{OHCs}$ from 4 animals) and Myo15 jd/jd littermates (972 OHCs from 4 animals). All images and quantification are from the midcochlear turn. Scale bars, $1 \mu \mathrm{m}$.

\section{FIGURE S3}

234 Immunofluorescence (IF) confocal images of anti-EPS8, anti-WHRN, anti-GNAI3 labelling or anti-

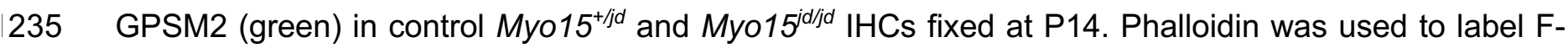


bioRxiv preprint doi: https://doi.org/10.1101/2021.07.09.451618; this version posted July 13, 2021. The copyright holder for this preprint (which was not certified by peer review) is the author/funder, who has granted bioRxiv a license to display the preprint in perpetuity. It is made available under aCC-BY-NC-ND 4.0 International license.

236 actin (magenta). Images are representative of data from two independent animals per genotype and 237 antibody combination. Scale bars, $10 \mu \mathrm{m}$. 


\section{FIGURE 1}
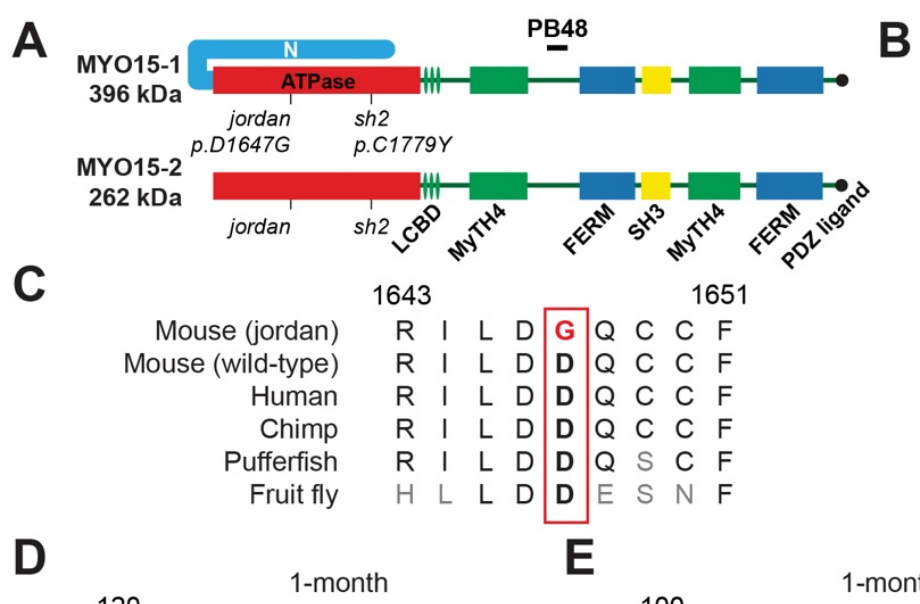

\section{E}
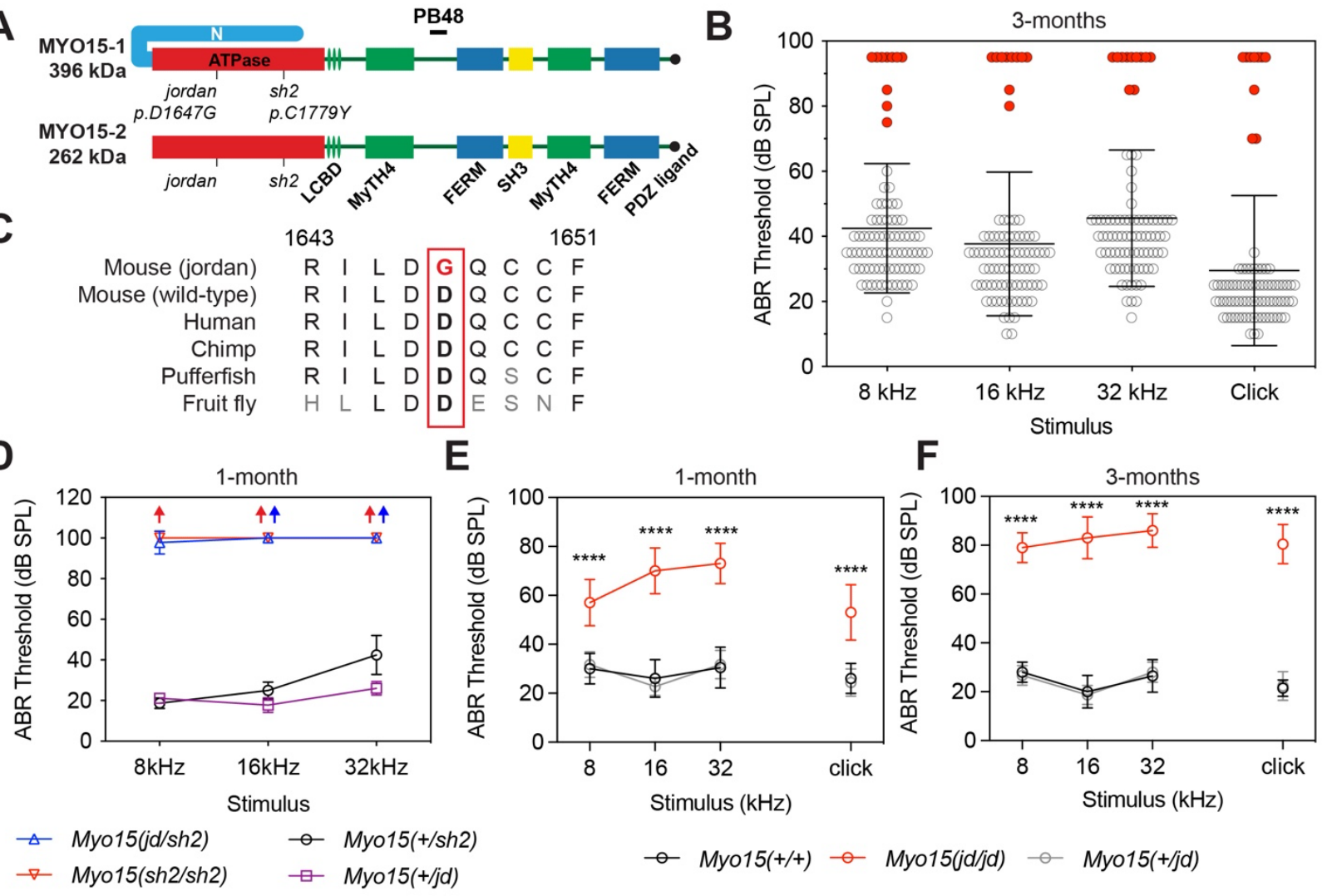

Stimulus $(\mathrm{kHz})$

Myo15(jd/jd) $\rightarrow$ Myo15(+/jd) 

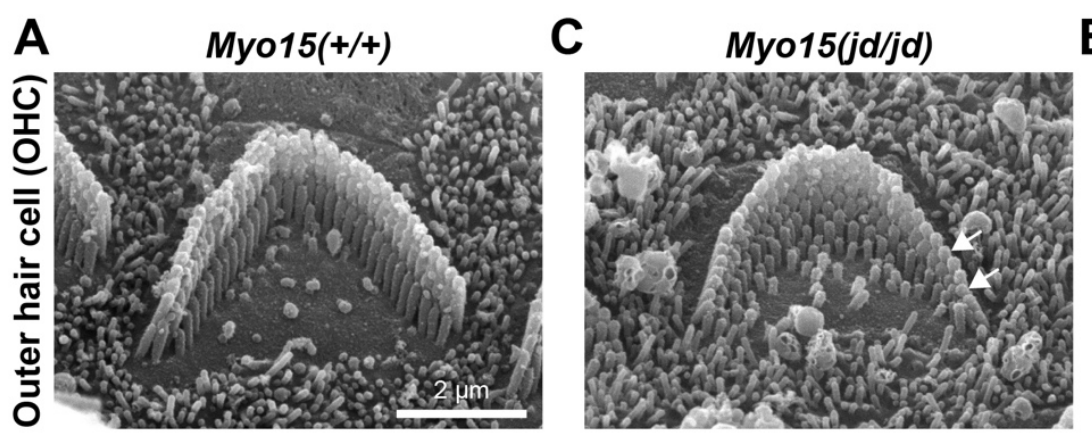

E Myo15(sh2/sh2)

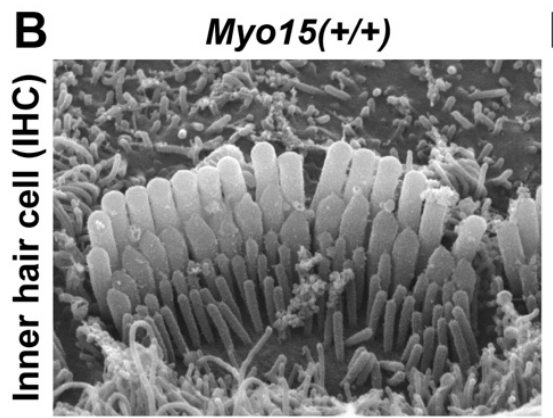

D Myo15(jd/jd)

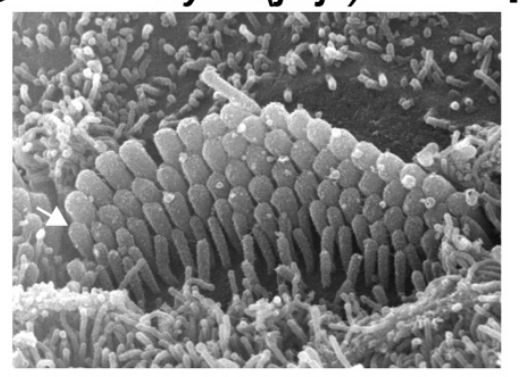

$\mathbf{F}$

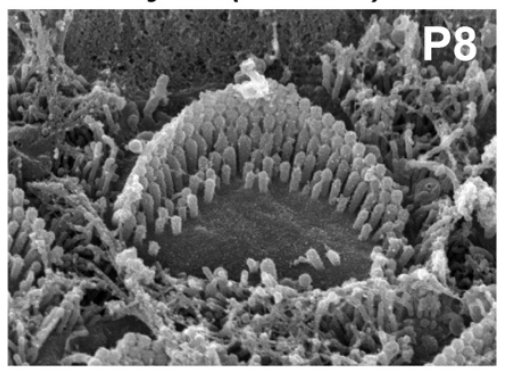

$\mathbf{G}$

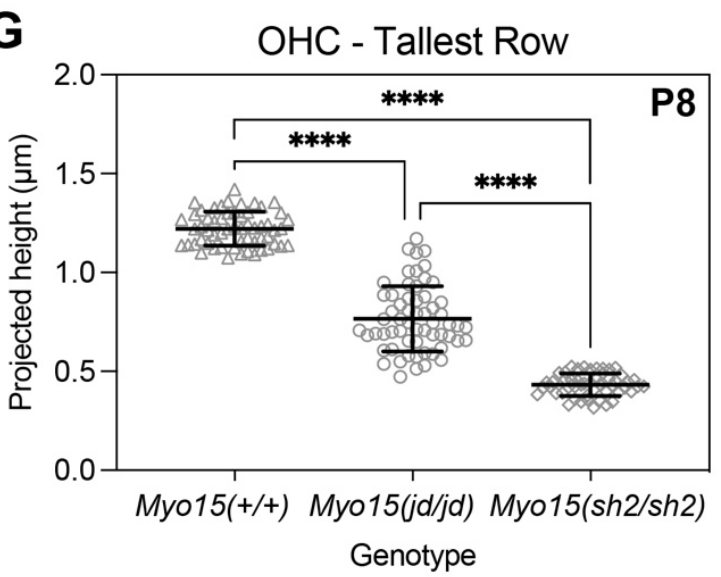

H

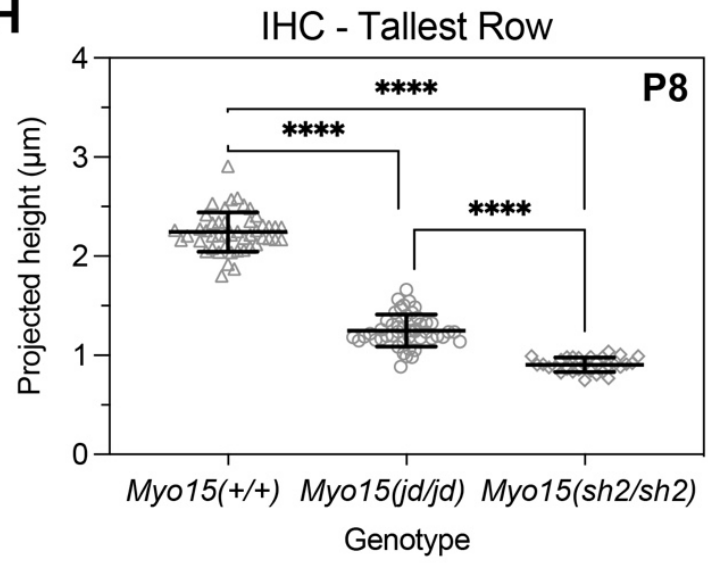


bioRxiv preprint doi: https://doi.org/10.1101/2021.07.09.451618; this version posted July 13, 2021. The copyright holder for this preprint (which was not certified by peer review) is the author/funder, who has granted bioRxiv a license to display the preprint in perpetuity. It is made available under aCC-BY-NC-ND 4.0 International license.

\section{FIGURE 3}

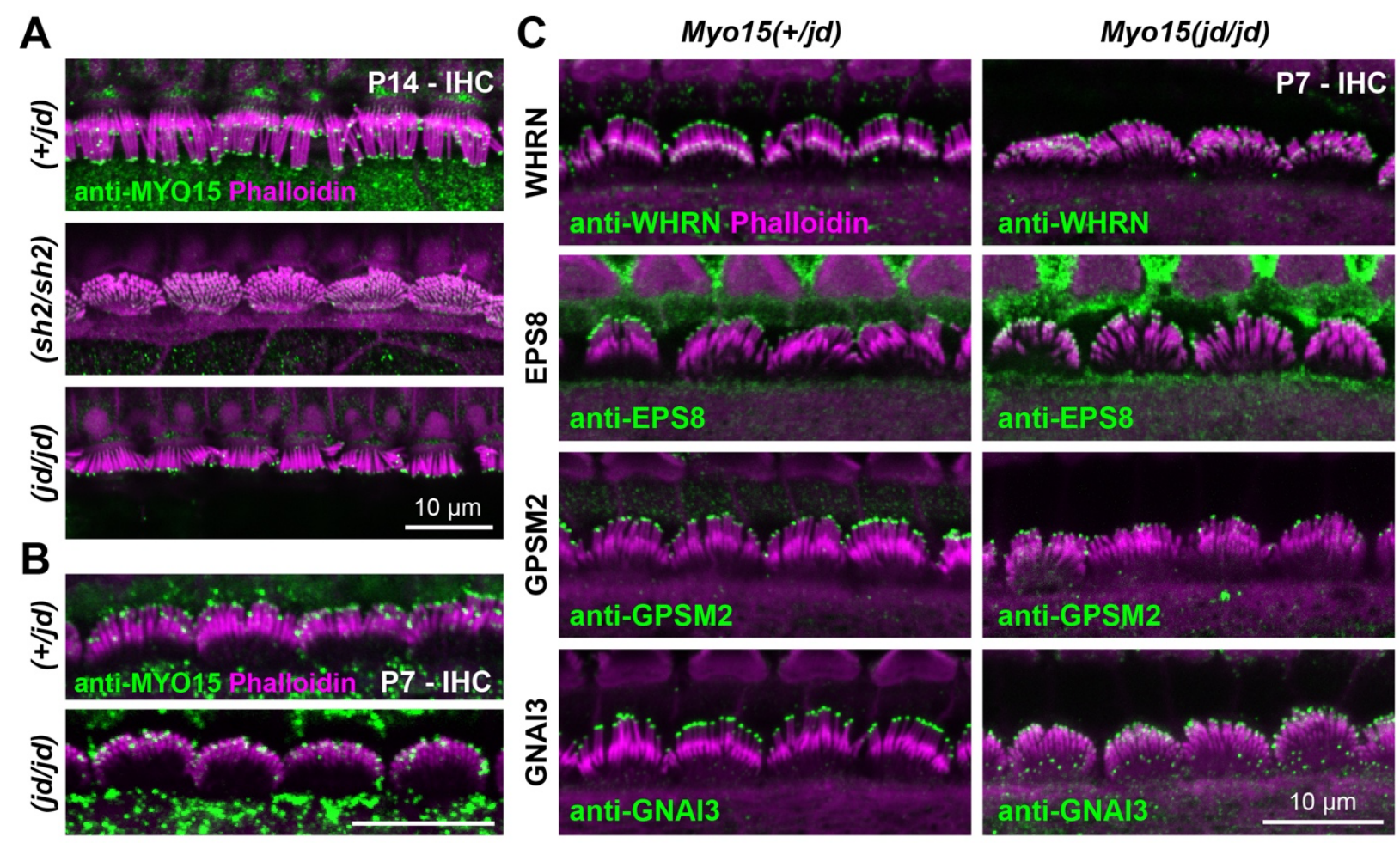


FIGURE 4

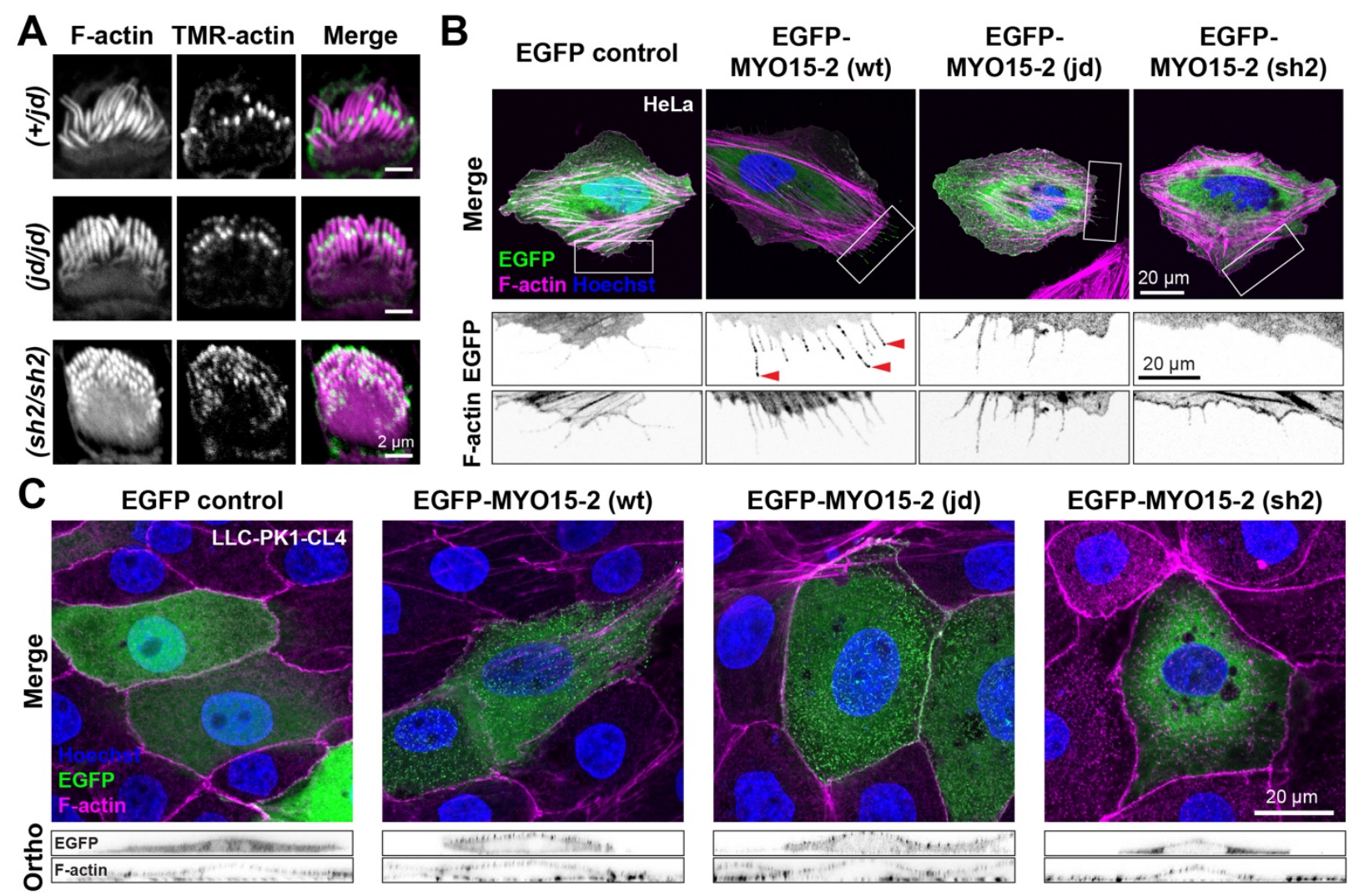




\section{FIGURE 5}

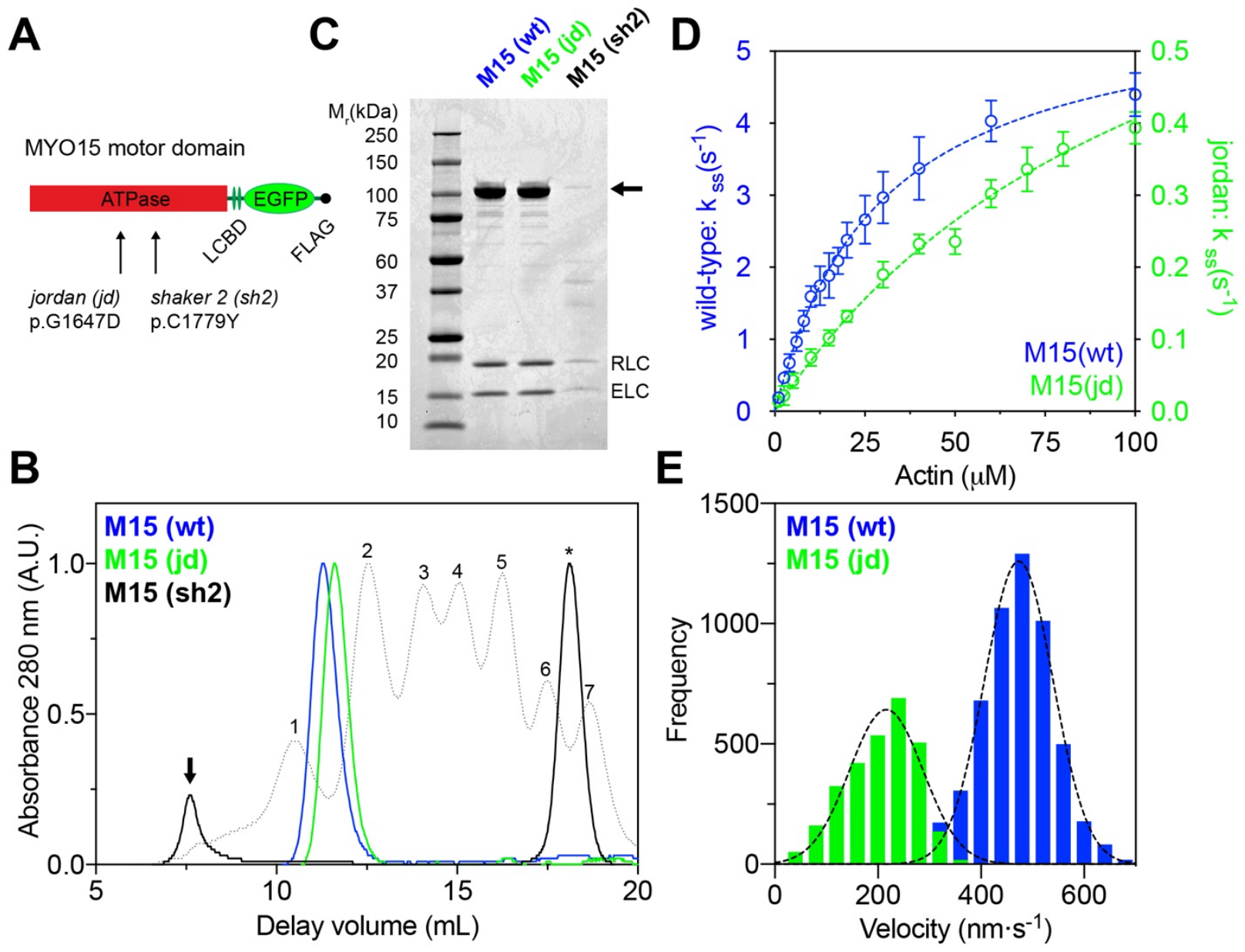




\section{FIGURE 6}

A

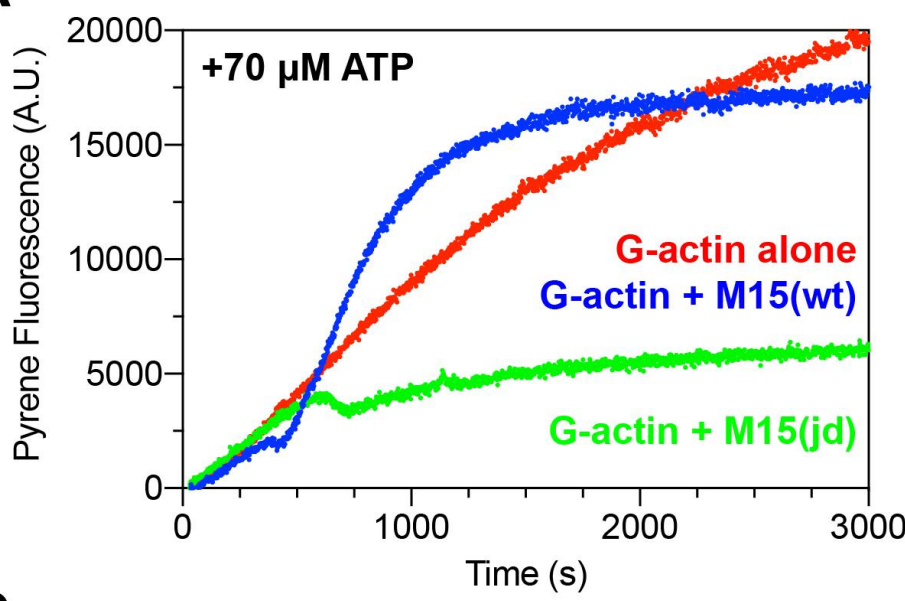

C

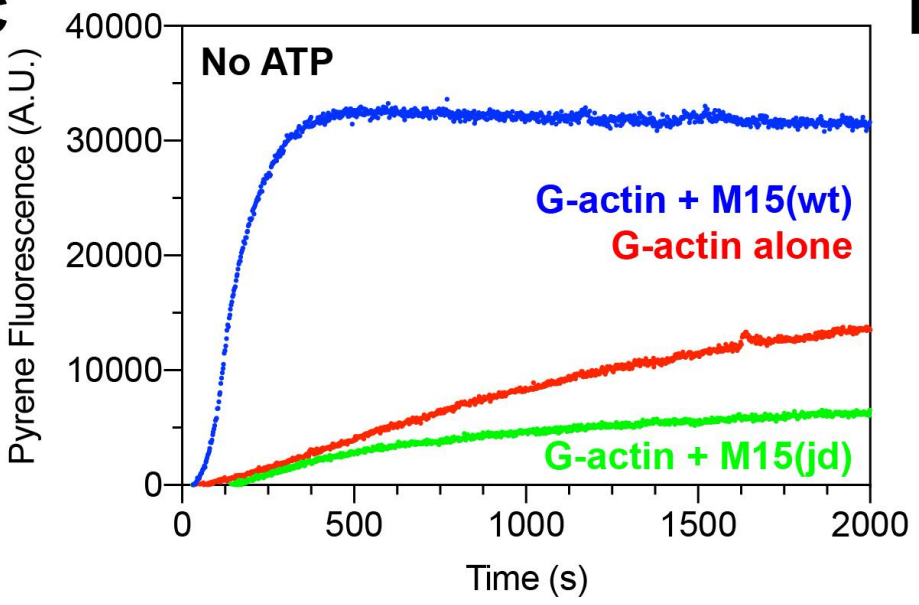

B
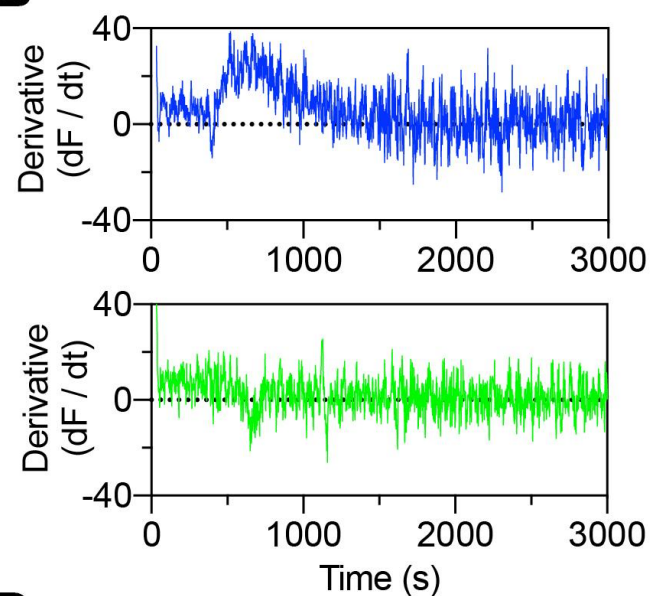

D ${ }_{2000}$

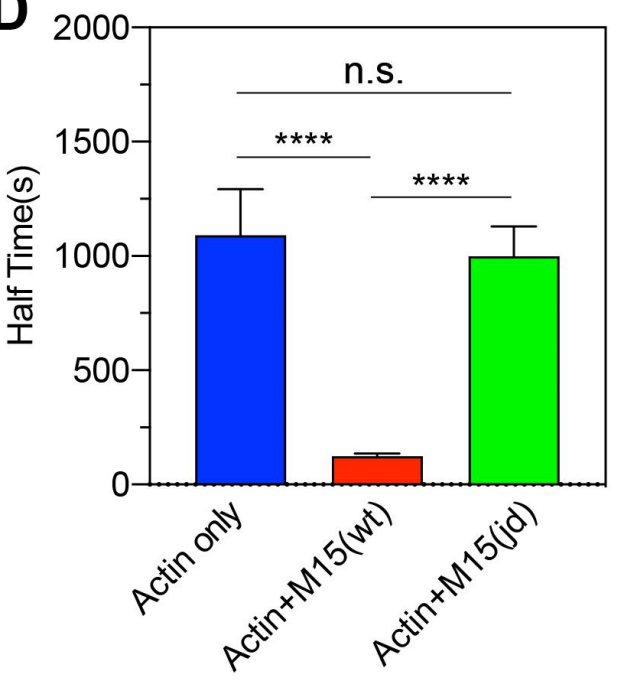




\section{FIGURE 7}
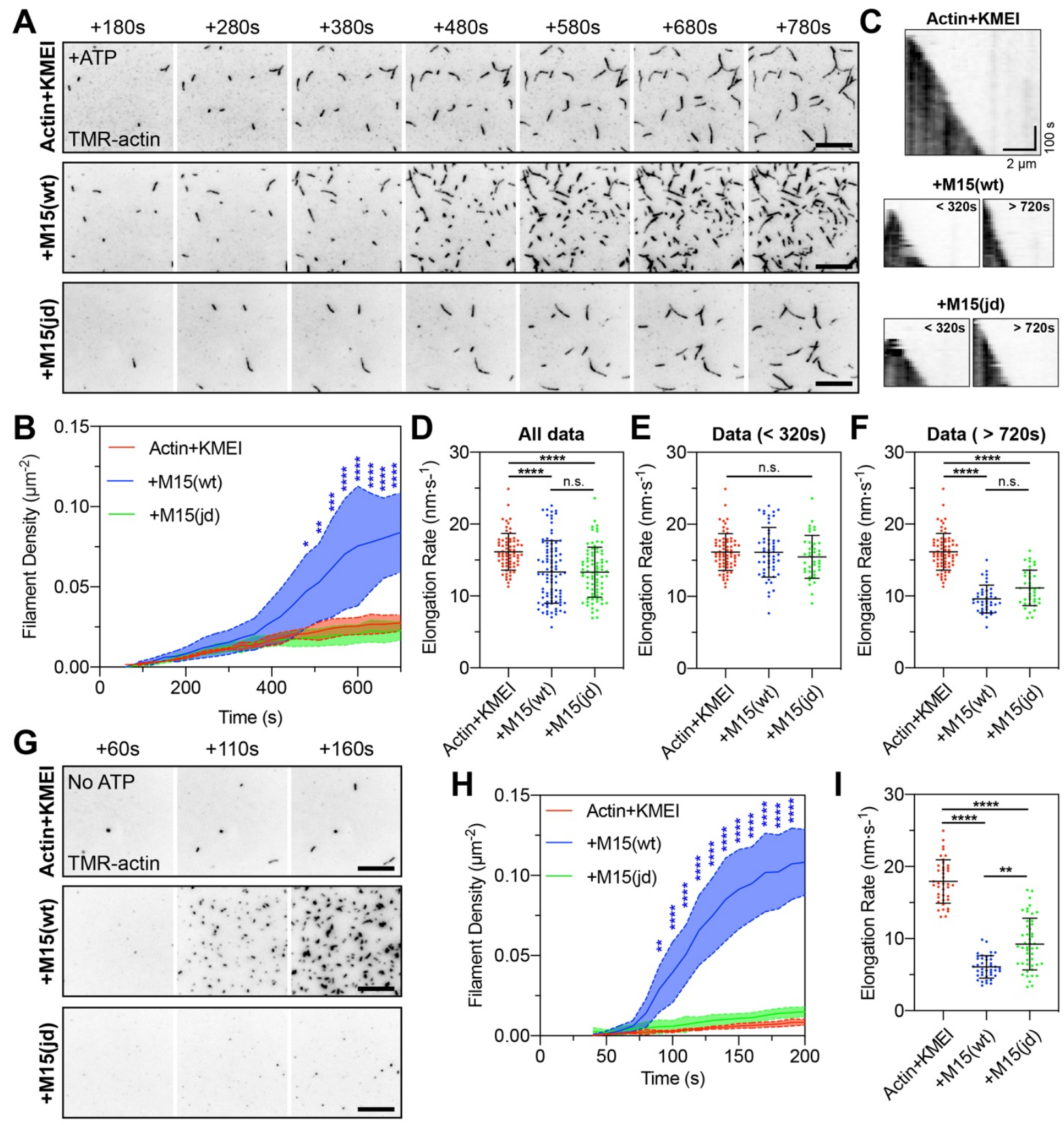
bioRxiv preprint doi: https://doi.org/10.1101/2021.07.09.451618; this version posted July 13,2021 . The copyright holder for this preprint (which was not certified by peer review) is the author/funder, who has granted bioRxiv a license to display the preprint in perpetuity. It is made available under aCC-BY-NC-ND 4.0 International license.

\section{FIGURE S1}

A

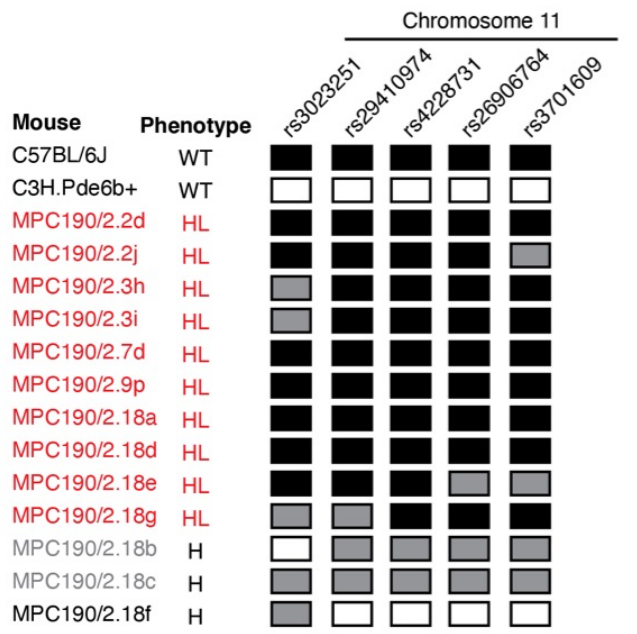

C

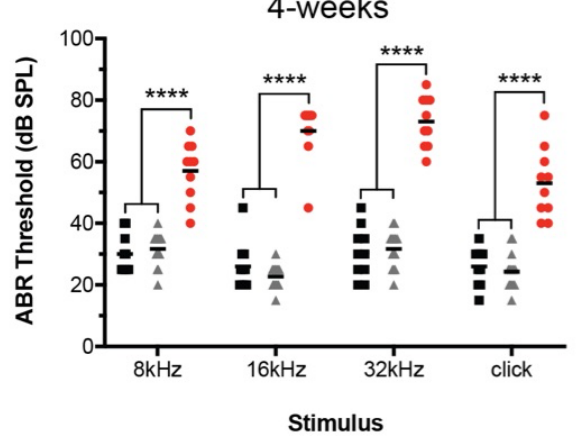

E

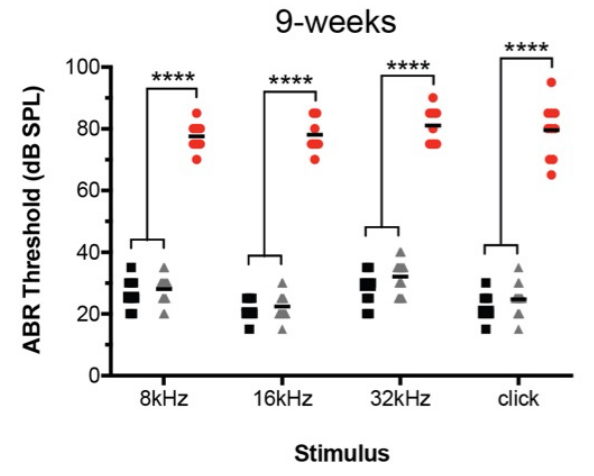

G

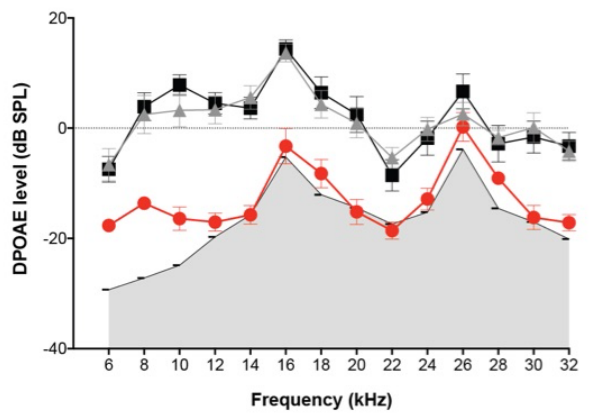

B

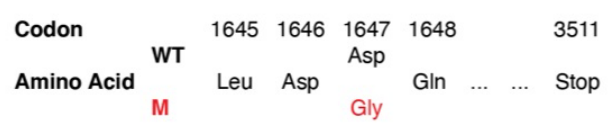

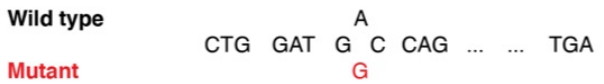

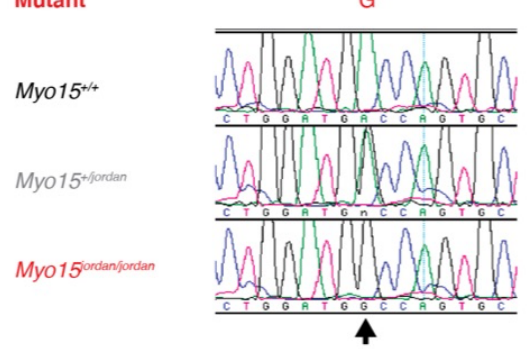

D

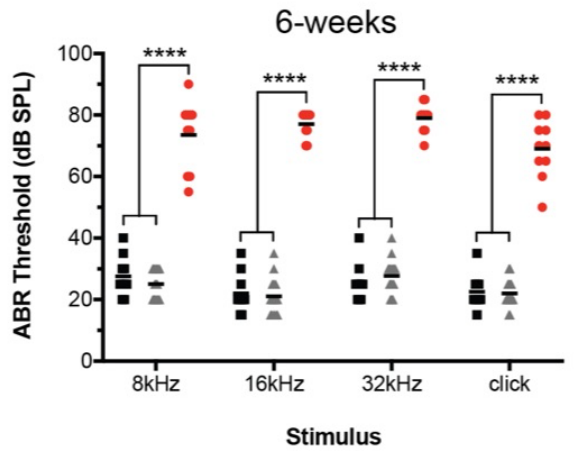

F

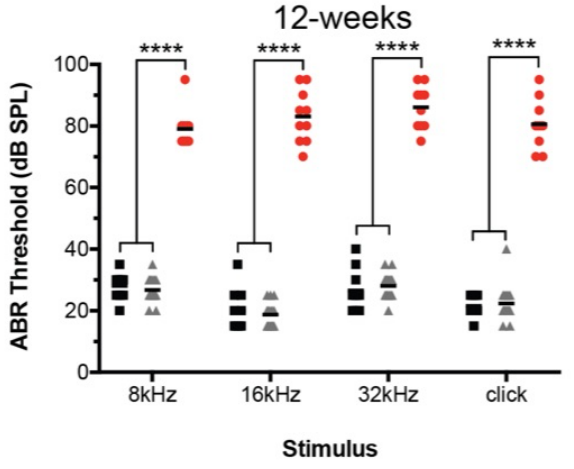

Myo15 $+1+$

-Myo15 $\mathrm{dn/t}$ 


\section{FIGURE S2}
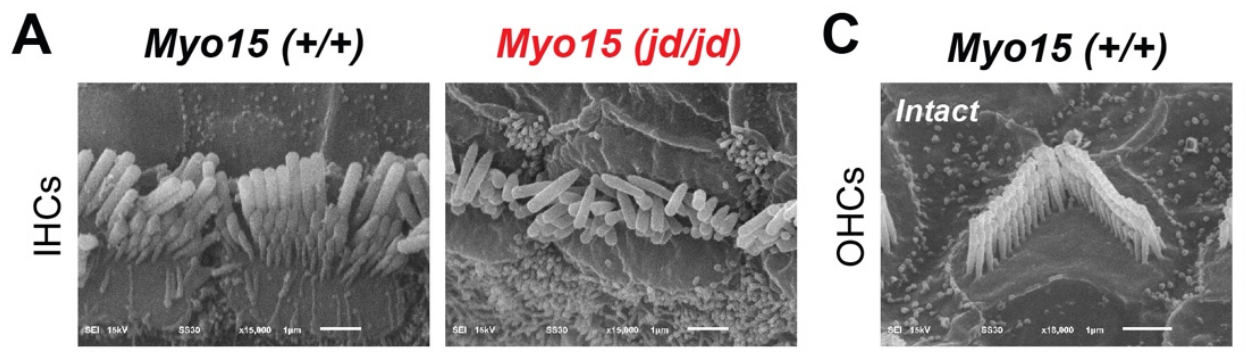

Myo15 (jd/jd)
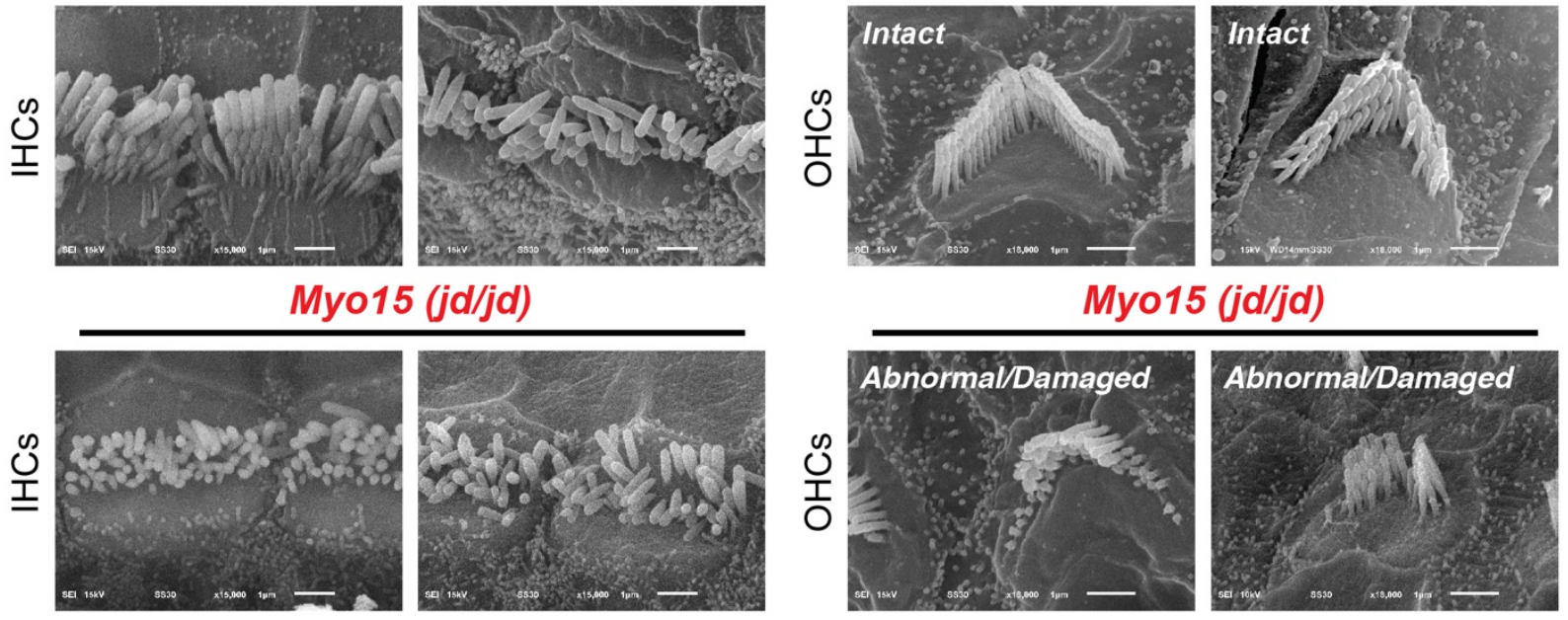

B

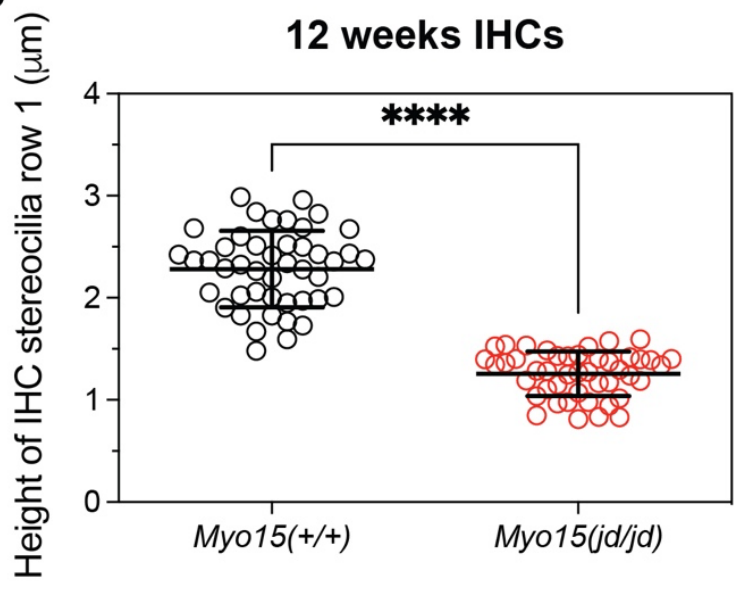

D

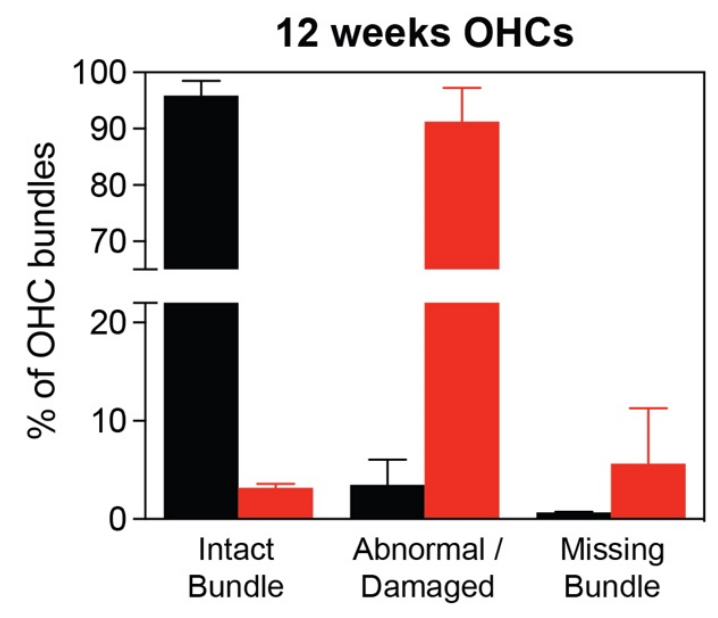

Myo15(+/+) Myo15 (jd/jd) 
bioRxiv preprint doi: https://doi.org/10.1101/2021.07.09.451618; this version posted July 13, 2021. The copyright holder for this preprint (which was not certified by peer review) is the author/funder, who has granted bioRxiv a license to display the preprint in perpetuity. It is made available under aCC-BY-NC-ND 4.0 International license.

\section{FIGURE S3}

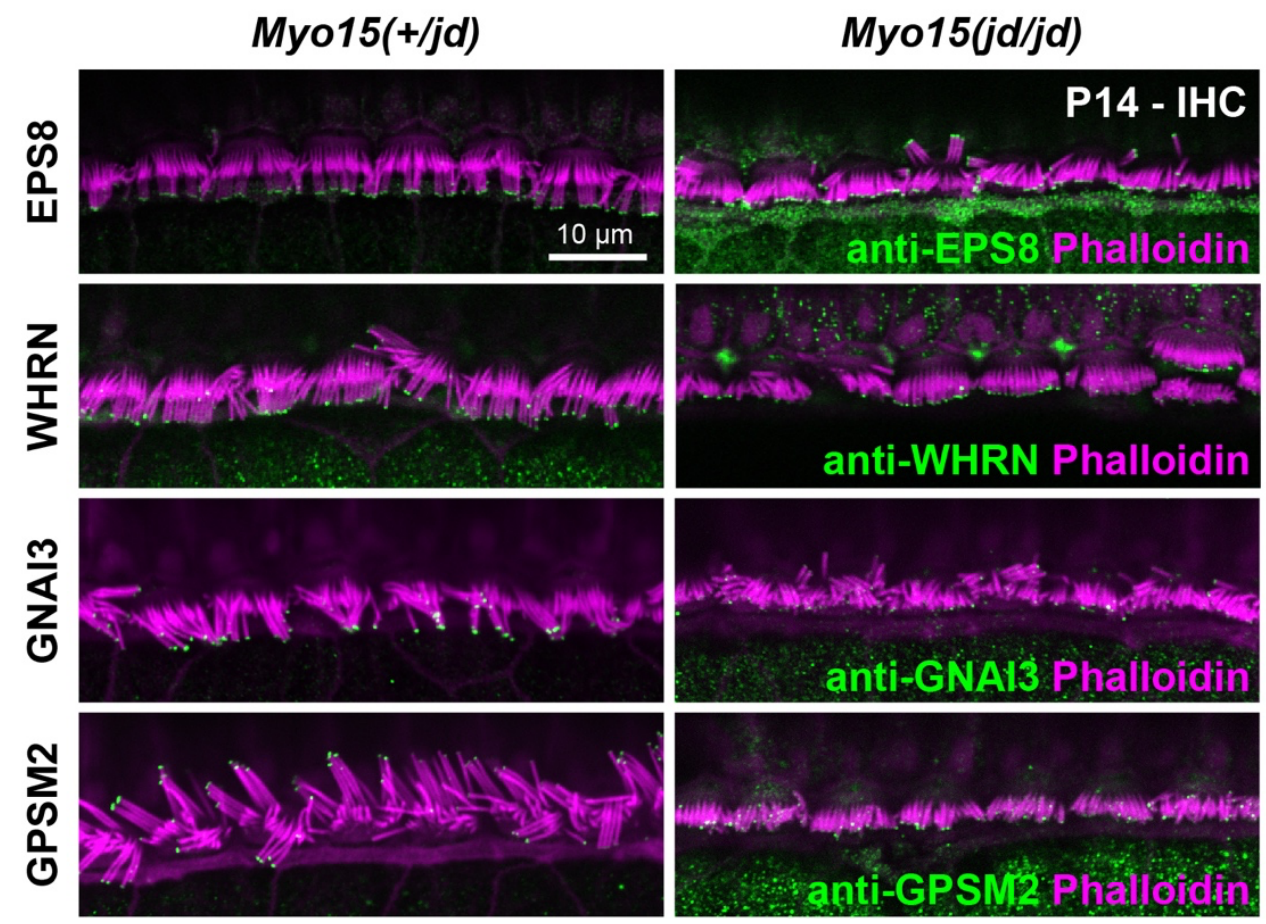

